\title{
NUMERICAL ASSESSMENT OF A VENTING SYSTEM WITH MULTI- CHAMBER MUFFLERS BY GA METHOD
}

\author{
Min-Chie Chiu \\ Changhua County, Taiwan, R.O.C., minchie.chiu@msa.hinet.net \\ Ying-Chun Chang \\ Department of Mechanical Engineering, Tatung University, Taipei, Taiwan, R.O.C.
}

Department of Mechanical and Automation Engineering, Chung Chou University of Science and Technology,

Follow this and additional works at: https://jmstt.ntou.edu.tw/journal

Part of the Engineering Commons

\section{Recommended Citation}

Chiu, Min-Chie and Chang, Ying-Chun (2011) "NUMERICAL ASSESSMENT OF A VENTING SYSTEM WITH MULTICHAMBER MUFFLERS BY GA METHOD," Journal of Marine Science and Technology: Vol. 19: Iss. 5, Article 4. DOI: $10.51400 / 2709-6998.2162$

Available at: https://jmstt.ntou.edu.tw/journal/vol19/iss5/4

This Research Article is brought to you for free and open access by Journal of Marine Science and Technology. It has been accepted for inclusion in Journal of Marine Science and Technology by an authorized editor of Journal of Marine Science and Technology. 


\section{NUMERICAL ASSESSMENT OF A VENTING SYSTEM WITH MULTI-CHAMBER}

MUFFLERS BY GA METHOD

\section{Acknowledgements}

The authors acknowledge the financial support of the National Science Council (NSC97-2221-E-235-001), ROC. 


\title{
NUMERICAL ASSESSMENT OF A VENTING SYSTEM WITH MULTI-CHAMBER MUFFLERS BY GA METHOD
}

\author{
Min-Chie Chiu* and Ying-Chun Chang**
}

Key words: multi-chamber perforated muffler, four-pole method, back pressure, GA method.

\begin{abstract}
Recently, research on new techniques of single-chamber perforated silencers has been addressed. However, the research work on shape optimization of multi-chamber silencers within a compact volume is rare. Work on the maximal allowable back pressure of mufflers has also been neglected. Therefore, the main purpose of this paper is to analyze the sound transmission loss (STL) of a space-constrained multi-chamber muffler and to optimize the best design shape under a specified pressure drop. In this paper, both the generalized decoupling technique and plane wave theory used to solve the coupled acoustical problem of multi-chamber perforated mufflers are presented. The four-pole system matrix used to evaluate the acoustic performance of sound transmission loss STL, is also presented in conjunction with the genetic algorithm (GA). In addition, numerical cases of sound elimination with respect to three kinds of multi-chamber mufflers (one-chamber, twochamber, and three-chamber mufflers) at various pure tones $(200,500 \mathrm{~Hz})$ are discussed. Before the GA operation can be carried out, the accuracy of the mathematical models is checked using Crocker's experimental data. The result reveals that to achieve a better acoustical performance under a specified maximal allowable pressure drop, a sacrifice of the acoustical performance to depress the muffler's back pressure is required. As a result, the optimal STL of three kinds of mufflers under a specified maximal allowable pressure drop of $600(\mathrm{~Pa})$ can be achieved at the targeted frequencies. Consequently, the approach used for the optimal design of the multichamber mufflers under space and back-pressure's constrained conditions is quite effective.
\end{abstract}

\footnotetext{
Paper submitted 11/03/09; revised 05/19/10; accepted 05/21/10. Author for correspondence: Min-Chie Chiu (e-mail:minchie.chiu@msa.hinet.net).

*Department of Mechanical and Automation Engineering, Chung Chou University of Science and Technology, Changhua County, Taiwan, R.O.C.

**Department of Mechanical Engineering, Tatung University, Taipei, Taiwan, R.O.C.
}

\section{INTRODUCTION}

It is obvious that noise levels can be harmful and can lead to psychological and physiological symptoms [1]. Therefore, the demand of low-noise levels of various products has become vital [7]. To overcome the low frequency noise emitted from a venting system, a reactive muffler is customarily used [8]. Moreover, to achieve the steady state of a volume-flow-rate emitted from a venting system going through a muffler, limited muffler back pressure within an allowable range is compulsory. Also, because the constrained problem is related to operation and maintenance in practical engineering work, there is a growing need to optimize the acoustical performance within a confined space.

In the past decade, to increase the acoustical performance, the assessment of new acoustical elements - internal perforated plug and non-plug tubes - was initiated by Sullivan and Crocker in 1978 [15]. Based on the coupled equations derived by Sullivan and Crocker, a series of theories and numerical techniques in decoupling the acoustical problems had been proposed $[5,11,14,16]$. Concerning the flowing effect, Munjal [9] and Peat [12] published the generalized decoupling and numerical decoupling methods. In 1992, Munjal et al. [10] investigated the acoustical and the back pressure effect of design parameters for perforated resonator mufflers, plug mufflers, and cross-flow perforated mufflers. However, the assessment of the muffler's optimal shape design within a constrained space was rarely addressed. In previous work [2, 3, 17], the shape optimization of a multi-chamber non-perforated muffler had been discussed; however, the effect of the system's back pressure, which may cause the decrement of the flow rate in a system, had not been considered.

In order to improve the performance of the noise control device under a specified pressure drop, a multi-chamber perforated muffler hybridized with perforated ducts is presented. To appreciate the chamber effect, the acoustical performance and back pressure in a blower room is shown in Fig. 1. Three kinds of mufflers (a one-chamber muffler, two-chamber muffler, and a three-chamber muffler) are proposed and investigated. Additionally, to avoid a possible overloaded pressure drop in the mufflers, a specified allowable pressure drop has been considered along with the process of the GA optimization. 


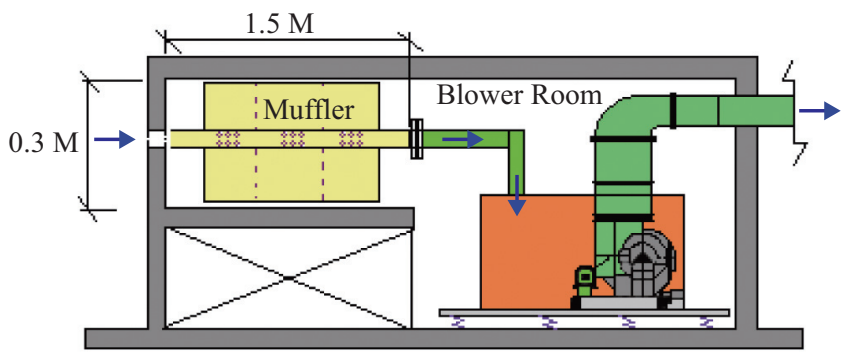

Fig. 1. A blower confined within a RC (reinforced concrete) room.

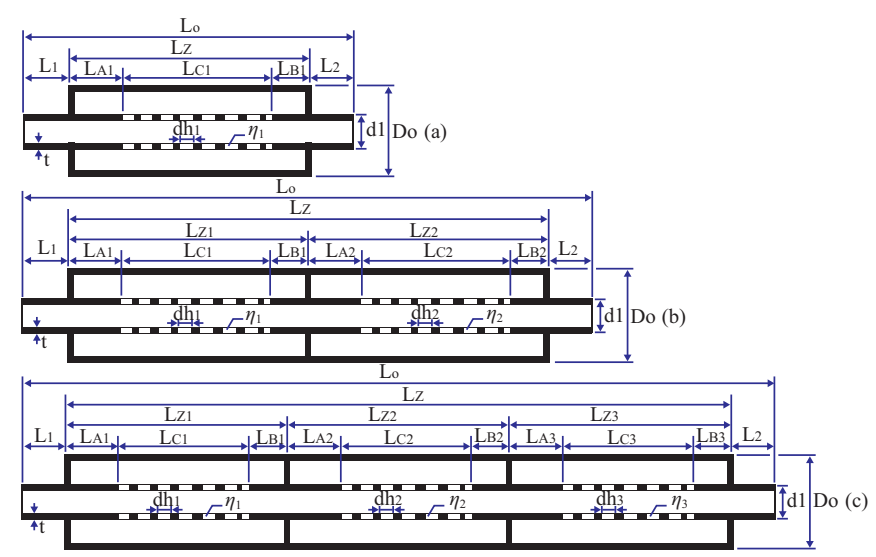

Fig. 2. The outlines of three kinds of multi-chamber perforated mufflers.

By using a genetic algorithm (GA), the muffler's performance is improved under a specified back-pressure value. To illuminate the compromise between the acoustical performance and the pressure drop, the optimal shape design without backpressure constraint has also been carried out. The results between the back-pressure's constraint and the non-constraint situation have been compared. In this paper, the numerical decoupling methods used in forming a four-pole system matrix are in tune with the above GA method. These, in turn, are responsible for developing a new muffler shape by adjusting the perforated muffler and required back pressure limits within the space constraints. By adjusting the muffler's shape and using the GA method and numerical decoupling methods, the optimal acoustical performances of mufflers with acceptable back pressure can be achieved.

\section{MATHEMATICAL MODELS}

The outlines of three kinds of multi-chamber mufflers (a one-chamber, two-chamber, and a three-chamber muffler) hybridized with perforated tubes and selected as the noisereduction devices are shown in Figs. 2(a), 2(b), and 2(c).

The acoustical fields with respect to various mufflers (a one-chamber, two-chamber, and a three-chamber plug muffler) are shown in Figs. 3(a), 3(b), and 3(c). As indicated in Figs. 2(a) and 3(a), the one-chamber muffler composed of four acoustical elements is identified with two categories of

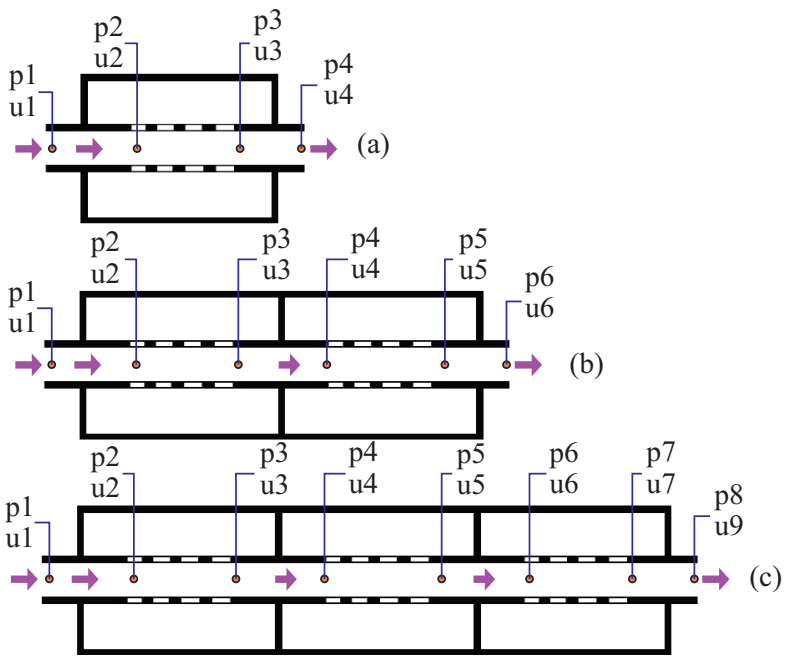

Fig. 3. The acoustical fields of three kinds of multi-chamber perforated mufflers.

components - two straight ducts and one perforated duct. The related acoustic pressure $p$ and acoustic particle velocity $u$ within the muffler are represented by four nodes. As indicated in Figs. 2(b) and 3(b), the two-chamber muffler consisting of five acoustical elements is also identified with two categories of components - three straight ducts and two perforated ducts. The related acoustic pressure $p$ and acoustic particle velocity $u$ within the muffler are represented by six nodes. Consequently, the three-chamber muffler shown in Figs. 2(c) and 3(c) is composed of seven acoustical elements and identified with two categories of components - four straight ducts and three perforated ducts. Eight nodes inside the acoustical elements represent the acoustical properties in the acoustical field with acoustic pressure $p$ and acoustic particle velocity $u$. The detailed mathematical derivation of various muffler systems is described below.

\section{A One-Chamber Muffler}

As derived in the Appendix A and previous papers [2, 3, 17], $\mathrm{B}$, and $\mathrm{C}$, individual transfer matrixes with respect to each case of straight ducts and perforated ducts are described as follows:

$$
\left(\begin{array}{c}
p_{1} \\
\rho_{o} c_{o} u_{1}
\end{array}\right)=e^{-j M_{1} k\left(L_{1}+L_{A 1}\right) /\left(1-M_{1}^{2}\right)}\left[\begin{array}{cc}
T S 1_{1,1} & T S 1_{1,2} \\
T S 1_{2,1} & T S 1_{2,2}
\end{array}\right]\left(\begin{array}{c}
p_{2} \\
\rho_{o} c_{o} u_{2}
\end{array}\right)
$$

$$
\begin{gathered}
T S 1_{1,1}=\cos \left[\frac{k\left(L_{1}+L_{A 1}\right)}{1-M_{1}^{2}}\right] ; T S 1_{1,2}=j \sin \left[\frac{k\left(L_{1}+L_{A 1}\right)}{1-M_{1}^{2}}\right] ; \\
T S 1_{2,1}=j \sin \left[\frac{k\left(L_{1}+L_{A 1}\right)}{1-M_{1}^{2}}\right] ; T S 1_{2,2}=\cos \left[\frac{k\left(L_{1}+L_{A 1}\right)}{1-M_{1}^{2}}\right] \\
\left(\begin{array}{c}
p_{2} \\
\rho_{o} c_{o} u_{2}
\end{array}\right)=\left[\begin{array}{ll}
T P 2_{1,1} & T P 2_{1,2} \\
T P 2_{2,1} & T P 2_{2,2}
\end{array}\right]\left(\begin{array}{c}
p_{3} \\
\rho_{o} c_{o} u_{3}
\end{array}\right)
\end{gathered}
$$


$\left(\begin{array}{c}p_{3} \\ \rho_{o} c_{o} u_{3}\end{array}\right)=e^{-j M_{3} k\left(L_{B 1}+L_{2}\right) /\left(1-M_{3}^{2}\right)}\left[\begin{array}{cc}T S 3_{1,1} & T S 3_{1,2} \\ T S 3_{2,1} & T S 3_{2,2}\end{array}\right]\left(\begin{array}{c}p_{4} \\ \rho_{o} c_{o} u_{4}\end{array}\right)$

$T S 3_{1,1}=\cos \left[\frac{k\left(L_{B 1}+L_{2}\right)}{1-M_{3}^{2}}\right] ; T S 3_{1,2}=j \sin \left[\frac{k\left(L_{B 1}+L_{2}\right)}{1-M_{3}^{2}}\right]$

$T S 3_{2,1}=j \sin \left[\frac{k\left(L_{B 1}+L_{2}\right)}{1-M_{3}^{2}}\right] ; T S 3_{2,2}=\cos \left[\frac{k\left(L_{B 1}+L_{2}\right)}{1-M_{3}^{2}}\right]$

The total transfer matrix assembled by multiplication is

$$
\begin{aligned}
\left(\begin{array}{c}
p_{1} \\
\rho_{o} c_{o} u_{1}
\end{array}\right)= & e^{-j k\left[\frac{M_{1}\left(L_{1}+L_{A 1}\right)}{1-M_{1}^{2}}+\frac{M_{3}\left(L_{B 1}+L_{2}\right)}{1-M_{3}^{2}}\right]}\left[\begin{array}{ll}
T S 1_{1,1} & T S 1_{1,2} \\
T S 1_{2,1} & T S 1_{2,2}
\end{array}\right] \\
& {\left[\begin{array}{ll}
T P 2_{1,1} & T P 2_{1,2} \\
T P 2_{2,1} & T P 2_{2,2}
\end{array}\right]\left[\begin{array}{ll}
T S 3_{1,1} & T S 3_{1,2} \\
T S 3_{2,1} & T S 3_{2,2}
\end{array}\right]\left(\begin{array}{c}
p_{4} \\
\rho_{o} c_{o} u_{4}
\end{array}\right) }
\end{aligned}
$$

A simplified form of a matrix is expressed as

$$
\left(\begin{array}{c}
p_{1} \\
\rho_{o} c_{o} u_{1}
\end{array}\right)=\left[\begin{array}{cc}
T_{11}^{*} & T_{12}^{*} \\
T_{21}^{*} & T_{22}^{*}
\end{array}\right]\left(\begin{array}{c}
p_{5} \\
\rho_{o} c_{o} u_{5}
\end{array}\right)
$$

The sound transmission loss (STL) of a muffler is defined as [9]

$$
\begin{aligned}
& \operatorname{STL}_{1}\left(Q, f, A f f_{11}, A f f_{12}, A f f_{13}, \eta_{1}, d h_{1}, \Delta p_{a}\right) \\
& =20 \log \left(\frac{\left|T_{11}^{*}+T_{12}^{*}+T_{21}^{*}+T_{22}^{*}\right|}{2}\right)+10 \log \left(\frac{S_{1}}{S_{3}}\right)
\end{aligned}
$$

where

$$
\begin{aligned}
& A_{f 1}=L_{Z} / L_{o} ; A f f_{12}=L_{C 1 A} / L_{Z} ; A f f_{13}=d_{1} / D_{o} ; \\
& L_{A 1}=\left(L_{Z}-L_{C 1}\right)=L_{B 1} ; L_{1}=L_{2}=\left(L_{o}-L_{Z}\right) / 2
\end{aligned}
$$

According to the experimental investigation of back pressure for a concentric-tube resonator by Munjal et al. [10], the mean pressure drop $\left(\Delta p_{1}\right)$ of a one-chamber perforated muffler is

$$
\begin{gathered}
\Delta p_{1}=\mathrm{H}_{1 *}(0.87+0.06 \mathrm{x} 1) \\
\mathrm{H}_{1}=\rho V^{2} / 2 ; \mathrm{x} 1=4 L_{C 1} \eta_{1} / d_{1}
\end{gathered}
$$

To meet the system requirement of allowable maximal pressure drop $\left(\Delta p_{a}\right)$, the mean pressure drop $\left(\Delta p_{1}\right)$ should be governed as

$$
\left(\Delta p_{a}\right) \geq \Delta p_{1}
$$

\section{A Two-Chamber Muffler}

As indicated above, individual transfer matrixes, each with acoustical elements, are described as follows:

$$
\begin{aligned}
& \left(\begin{array}{c}
p_{1} \\
\rho_{o} c_{o} u_{1}
\end{array}\right)=e^{-j M_{1} k\left(L_{1}+L_{A 1}\right) /\left(1-M_{1}^{2}\right)}\left[\begin{array}{cc}
T S 1_{1,1} & T S 1_{1,2} \\
T S 1_{2,1} & T S 1_{2,2}
\end{array}\right]\left(\begin{array}{c}
p_{2} \\
\rho_{o} c_{o} u_{2}
\end{array}\right) \\
& T S 1_{1,1}=\cos \left[\frac{k\left(L_{1}+L_{A 1}\right)}{1-M_{1}^{2}}\right] ; T S 1_{1,2}=j \sin \left[\frac{k\left(L_{1}+L_{A 1}\right)}{1-M_{1}^{2}}\right] \\
& T S 1_{2,1}=j \sin \left[\frac{k\left(L_{1}+L_{A 1}\right)}{1-M_{1}^{2}}\right] ; T S 1_{2,2}=\cos \left[\frac{k\left(L_{1}+L_{A 1}\right)}{1-M_{1}^{2}}\right] \\
& \left(\begin{array}{c}
p_{2} \\
\rho_{o} c_{o} u_{2}
\end{array}\right)=\left[\begin{array}{cc}
T P 2_{1,1} & T P 2_{1,2} \\
T P 2_{2,1} & T P 2_{2,2}
\end{array}\right]\left(\begin{array}{c}
p_{3} \\
\rho_{o} c_{o} u_{3}
\end{array}\right) \\
& \left(\begin{array}{c}
p_{3} \\
\rho_{o} c_{o} u_{3}
\end{array}\right)=e^{-j M_{3} k\left(L_{B 1}+L_{A 2}\right) /\left(1-M_{3}^{2}\right)}\left[\begin{array}{cc}
T S 3_{1,1} & T S 3_{1,2} \\
T S 3_{2,1} & T S 3_{2,2}
\end{array}\right]\left(\begin{array}{c}
p_{4} \\
\rho_{o} c_{o} u_{4}
\end{array}\right)
\end{aligned}
$$

$$
\begin{aligned}
& T S 3_{1,1}=\cos \left[\frac{k\left(L_{B 1}+L_{A 2}\right)}{1-M_{3}^{2}}\right] ; T S 3_{1,2}=j \sin \left[\frac{k\left(L_{B 1}+L_{A 2}\right)}{1-M_{3}^{2}}\right] \\
& T S 3_{2,1}=j \sin \left[\frac{k\left(L_{B 1}+L_{A 2}\right)}{1-M_{3}^{2}}\right] ; T S 3_{2,2}=\cos \left[\frac{k\left(L_{B 1}+L_{A 2}\right)}{1-M_{3}^{2}}\right]
\end{aligned}
$$

$$
\left(\begin{array}{c}
p_{4} \\
\rho_{o} c_{o} u_{4}
\end{array}\right)=\left[\begin{array}{cc}
T P 4_{1,1} & T P 4_{1,2} \\
T P 4_{2,1} & T P 4_{2,2}
\end{array}\right]\left(\begin{array}{c}
p_{5} \\
\rho_{o} c_{o} u_{5}
\end{array}\right)
$$

$$
\left(\begin{array}{c}
p_{5} \\
\rho_{o} c_{o} u_{5}
\end{array}\right)=e^{-j M_{5} k\left(L_{B 2}+L_{2}\right) /\left(1-M_{5}^{2}\right)}\left[\begin{array}{cc}
T S 5_{1,1} & T S 5_{1,2} \\
T S 5_{2,1} & T S 5_{2,2}
\end{array}\right]\left(\begin{array}{c}
p_{6} \\
\rho_{o} c_{o} u_{6}
\end{array}\right)
$$

$$
\begin{aligned}
& T S 5_{1,1}=\cos \left[\frac{k\left(L_{B 2}+L_{2}\right)}{1-M_{5}^{2}}\right] ; T S 5_{1,2}=j \sin \left[\frac{k\left(L_{B 2}+L_{2}\right)}{1-M_{5}^{2}}\right] ; \\
& T S 5_{2,1}=j \sin \left[\frac{k\left(L_{B 2}+L_{2}\right)}{1-M_{5}^{2}}\right] ; T S 5_{2,2}=\cos \left[\frac{k\left(L_{B 2}+L_{2}\right)}{1-M_{5}^{2}}\right]
\end{aligned}
$$

The total transfer matrix assembled by multiplication is

$$
\begin{aligned}
\left(\begin{array}{c}
p_{1} \\
\rho_{o} c_{o} u_{1}
\end{array}\right)= & e^{-j k\left[\frac{M_{1}\left(L_{1}+L_{A 1}\right)}{1-M_{1}^{2}}+\frac{M_{3}\left(L_{B 1}+L_{A 2}\right)}{1-M_{3}^{2}}+\frac{M_{5}\left(L_{B 2}+L_{2}\right)}{1-M_{5}^{2}}\right]}\left[\begin{array}{ll}
T S 1_{1,1} & T S 1_{1,2} \\
T S 1_{2,1} & T S 1_{2,2}
\end{array}\right] \\
& {\left[\begin{array}{ll}
T P 2_{1,1} & T P 2_{1,2} \\
T P 2_{2,1} & T P 2_{2,2}
\end{array}\right]\left[\begin{array}{ll}
T S 3_{1,1} & T S 3_{1,2} \\
T S 3_{2,1} & T S 3_{2,2}
\end{array}\right] }
\end{aligned}
$$




$$
\left[\begin{array}{ll}
T P 4_{1,1} & T P 4_{1,2} \\
T P 4_{2,1} & T P 4_{2,2}
\end{array}\right]\left[\begin{array}{ll}
T S 5_{1,1} & T S 5_{1,2} \\
T S 5_{2,1} & T S 5_{2,2}
\end{array}\right]\left(\begin{array}{c}
p_{6} \\
\rho_{o} c_{o} u_{6}
\end{array}\right)
$$

A simplified form of a matrix is expressed as

$$
\left(\begin{array}{c}
p_{1} \\
\rho_{o} c_{o} u_{1}
\end{array}\right)=\left[\begin{array}{cc}
T_{11}^{*} & T_{12}^{*} \\
T_{21}^{*} & T_{22}^{*}
\end{array}\right]\left(\begin{array}{c}
p_{6} \\
\rho_{o} c_{o} u_{6}
\end{array}\right)
$$

Similarly, the sound transmission loss (STL) of a muffler is $\mathrm{STL}_{2}\left(Q, f, A_{f 1}, A f f_{22}, A f f_{23}, A f f_{24}, A f f_{25}, \eta_{1}, d h_{1}, \eta_{2}, d h_{2}, \Delta p_{a}\right)$ $=20 \log \left(\frac{\left|T_{11}^{*}+T_{12}^{*}+T_{21}^{*}+T_{22}^{*}\right|}{2}\right)+10 \log \left(\frac{S_{1}}{S_{5}}\right)$

where

$A f f_{21}=L_{Z} / L_{o} ; A f f_{22}=L_{Z 1} / L_{Z} ; A f f_{23}=L_{C 1} / L_{Z 1} ; A f f_{24}=L_{C 2} / L_{Z 2} ;$

$A f f_{25}=d_{1} / D_{o} ; L_{Z 2}=L_{Z}-L_{Z 1} ; L_{A 1}=\left(L_{Z 1}-L_{C 1}\right) / 2=L_{B 1} ;$

$L_{A 2}=\left(L_{Z 2}-L_{C 2}\right) / 2=L_{B 2} ; L_{1}=L_{2}=\left(L_{o}-L_{Z}\right) / 2$;

Equally, the mean pressure drop $\left(\Delta p_{2}\right)$ of a two-chamber plug muffler is

$$
\begin{aligned}
\Delta p_{2} & =\mathrm{H}_{2} *[(0.87+0.06 \mathrm{x} 1)+(0.87+0.06 \times 2)] \\
\mathrm{H}_{2} & =\rho V^{2} / 2 ; \mathrm{x} 1=4 L_{C 1} \eta_{1} / d_{1} ; \mathrm{x} 2=4 L_{C 2} \eta_{2} / d_{1}
\end{aligned}
$$

To meet the system requirement of allowable maximal pressure drop $\left(\Delta p_{a}\right)$, the mean pressure drop $\left(\Delta p_{2}\right)$ should be governed as

$$
\left(\Delta p_{a}\right) \geq \Delta p_{2}
$$

\section{A Three-Chamber Muffler}

Similarly, individual transfer matrixes, each with acoustical elements, are described as follows:

$$
\begin{gathered}
\left(\begin{array}{c}
p_{1} \\
\rho_{o} c_{o} u_{1}
\end{array}\right)=e^{-j M_{1} k\left(L_{1}+L_{A 1}\right) /\left(1-M_{1}^{2}\right)}\left[\begin{array}{cc}
T S 1_{1,1} & T S 1_{1,2} \\
T S 1_{2,1} & T S 1_{2,2}
\end{array}\right]\left(\begin{array}{c}
p_{2} \\
\rho_{o} c_{o} u_{2}
\end{array}\right) \\
T S 1_{1,1}=\cos \left[\frac{k\left(L_{1}+L_{A 1}\right)}{1-M_{1}^{2}}\right] ; T S 1_{1,2}=j \sin \left[\frac{k\left(L_{1}+L_{A 1}\right)}{1-M_{1}^{2}}\right] ; \\
T S 1_{2,1}=j \sin \left[\frac{k\left(L_{1}+L_{A 1}\right)}{1-M_{1}^{2}}\right] ; T S 1_{2,2}=\cos \left[\frac{k\left(L_{1}+L_{A 1}\right)}{1-M_{1}^{2}}\right] \\
\left(\begin{array}{c}
p_{2} \\
\rho_{o} c_{o} u_{2}
\end{array}\right)=\left[\begin{array}{ll}
T P 2_{1,1} & T P 2_{1,2} \\
T P 2_{2,1} & T P 2_{2,2}
\end{array}\right]\left(\begin{array}{c}
p_{3} \\
\rho_{o} c_{o} u_{3}
\end{array}\right)
\end{gathered}
$$

$$
\left(\begin{array}{c}
p_{3} \\
\rho_{o} c_{o} u_{3}
\end{array}\right)=e^{-j M_{3} k\left(L_{B 1}+L_{A 2}\right) /\left(1-M_{3}^{2}\right)}\left[\begin{array}{ll}
T S 3_{1,1} & T S 3_{1,2} \\
T S 3_{2,1} & T S 3_{2,2}
\end{array}\right]\left(\begin{array}{c}
p_{4} \\
\rho_{o} c_{o} u_{4}
\end{array}\right)
$$

$$
\begin{aligned}
& T S 3_{1,1}=\cos \left[\frac{k\left(L_{B 1}+L_{A 2}\right)}{1-M_{3}^{2}}\right] ; T S 3_{1,2}=j \sin \left[\frac{k\left(L_{B 1}+L_{A 2}\right)}{1-M_{3}^{2}}\right] \\
& T S 3_{2,1}=j \sin \left[\frac{k\left(L_{B 1}+L_{A 2}\right)}{1-M_{3}^{2}}\right] ; T S 3_{2,2}=\cos \left[\frac{k\left(L_{B 1}+L_{A 2}\right)}{1-M_{3}^{2}}\right]
\end{aligned}
$$

$$
\left(\begin{array}{c}
p_{4} \\
\rho_{o} c_{o} u_{4}
\end{array}\right)=\left[\begin{array}{cc}
T P 4_{1,1} & T P 4_{1,2} \\
T P 4_{2,1} & T P 4_{2,2}
\end{array}\right]\left(\begin{array}{c}
p_{5} \\
\rho_{o} c_{o} u_{5}
\end{array}\right)
$$

$$
\left(\begin{array}{c}
p_{5} \\
\rho_{o} c_{o} u_{5}
\end{array}\right)=e^{-j M_{5} k\left(L_{B 2}+L_{A 3}\right) /\left(1-M_{5}^{2}\right)}\left[\begin{array}{cc}
T S 5_{1,1} & T S 5_{1,2} \\
T S 5_{2,1} & T S 5_{2,2}
\end{array}\right]\left(\begin{array}{c}
p_{6} \\
\rho_{o} c_{o} u_{6}
\end{array}\right)
$$

$$
\begin{aligned}
& T S 5_{1,1}=\cos \left[\frac{k\left(L_{B 2}+L_{A 3}\right)}{1-M_{5}^{2}}\right] ; T S 5_{1,2}=j \sin \left[\frac{k\left(L_{B 2}+L_{A 3}\right)}{1-M_{5}^{2}}\right] \\
& T S 5_{2,1}=j \sin \left[\frac{k\left(L_{B 2}+L_{A 3}\right)}{1-M_{5}^{2}}\right] ; T S 5_{2,2}=\cos \left[\frac{k\left(L_{B 2}+L_{A 3}\right)}{1-M_{5}^{2}}\right]
\end{aligned}
$$

$$
\left(\begin{array}{c}
p_{6} \\
\rho_{o} c_{o} u_{6}
\end{array}\right)=\left[\begin{array}{cc}
T P 6_{1,1} & T P 6_{1,2} \\
T P 6_{2,1} & T P 6_{2,2}
\end{array}\right]\left(\begin{array}{c}
p_{7} \\
\rho_{o} c_{o} u_{7}
\end{array}\right)
$$

$\left(\begin{array}{c}p_{7} \\ \rho_{o} c_{o} u_{7}\end{array}\right)=e^{-j M_{7} k\left(L_{B 3}+L_{2}\right) /\left(1-M_{7}^{2}\right)}\left[\begin{array}{cc}T S 7_{1,1} & T S 7_{1,2} \\ T S 5_{2,1} & T S 7_{2,2}\end{array}\right]\left(\begin{array}{c}p_{8} \\ \rho_{o} c_{o} u_{8}\end{array}\right)$

$$
\begin{aligned}
& T S 7_{1,1}=\cos \left[\frac{k\left(L_{B 3}+L_{2}\right)}{1-M_{7}^{2}}\right] ; T S 7_{1,2}=j \sin \left[\frac{k\left(L_{B 3}+L_{2}\right)}{1-M_{7}^{2}}\right] ; \\
& T S 7_{2,1}=j \sin \left[\frac{k\left(L_{B 3}+L_{2}\right)}{1-M_{7}^{2}}\right] ; T S 7_{2,2}=\cos \left[\frac{k\left(L_{B 3}+L_{2}\right)}{1-M_{7}^{2}}\right]
\end{aligned}
$$

The total transfer matrix assembled by multiplication is

$$
\begin{aligned}
\left(\begin{array}{c}
p_{1} \\
\rho_{o} c_{o} u_{1}
\end{array}\right)= & \left.e^{-j k\left[\frac{M_{1}\left(L_{1}+L_{A 1}\right)}{1-M_{1}^{2}}+\frac{M_{3}\left(L_{B 1}+L_{A 2}\right)}{1-M_{3}^{2}}+\frac{M_{5}\left(L_{B 2}+L_{A 3}\right)}{1-M_{5}^{2}}+\frac{M_{7}\left(L_{B 3}+L_{2}\right)}{1-M_{7}^{2}}\right]}\right] \\
& {\left[\begin{array}{ll}
T S 1_{1,1} & T S 1_{1,2} \\
T S 1_{2,1} & T S 1_{2,2}
\end{array}\right]\left[\begin{array}{ll}
T P 2_{1,1} & T P 2_{1,2} \\
T P 2_{2,1} & T P 2_{2,2}
\end{array}\right] } \\
& {\left[\begin{array}{ll}
T S 3_{1,1} & T S 3_{1,2} \\
T S 3_{2,1} & T S 3_{2,2}
\end{array}\right]\left[\begin{array}{ll}
T P 4_{1,1} & T P 4_{1,2} \\
T P 4_{2,1} & T P 4_{2,2}
\end{array}\right] }
\end{aligned}
$$




$$
\begin{aligned}
& {\left[\begin{array}{ll}
T S 5_{1,1} & T S 5_{1,2} \\
T S 5_{2,1} & T S 5_{2,2}
\end{array}\right]\left[\begin{array}{ll}
T P 6_{1,1} & T P 6_{1,2} \\
T P 6_{2,1} & T P 6_{2,2}
\end{array}\right]} \\
& {\left[\begin{array}{ll}
T S 7_{1,1} & T S 7_{1,2} \\
T S 7_{2,1} & T S 7_{2,2}
\end{array}\right]\left(\begin{array}{c}
p_{8} \\
\rho_{o} c_{o} u_{8}
\end{array}\right)}
\end{aligned}
$$

A simplified form of a matrix is expressed as

$$
\left(\begin{array}{c}
p_{1} \\
\rho_{o} c_{o} u_{1}
\end{array}\right)=\left[\begin{array}{cc}
T_{11}^{*} & T_{12}^{*} \\
T_{21}^{*} & T_{22}^{*}
\end{array}\right]\left(\begin{array}{c}
p_{8} \\
\rho_{o} c_{o} u_{8}
\end{array}\right)
$$

Also, the sound transmission loss (STL) of a muffler is

$$
\begin{aligned}
& \operatorname{STL}_{3}\left(Q, f, \operatorname{Aff}_{31}, \operatorname{Aff}_{32}, A f f_{33}, \operatorname{Aff}_{34}, \operatorname{Aff}_{35}, A f f_{36}, \eta_{1}, d h_{1}, \eta_{2},\right. \\
& \left.\quad d h_{2}, \eta_{3}, d h_{3}, \Delta p_{a}\right) \\
& =20 \log \left(\frac{\left|T_{11}^{*}+T_{12}^{*}+T_{21}^{*}+T_{22}^{*}\right|}{2}\right)+10 \log \left(\frac{S_{1}}{S_{7}}\right)
\end{aligned}
$$

where

$A f f_{31}=L_{Z} / L_{o} ; A f f_{32}=L_{Z 2} / L_{Z} ; A f f_{33}=L_{C 1} / L_{Z 1} ; A f f_{34}=L_{C 2} / L_{Z 2} ;$

$A f f_{35}=L_{C 3} / L_{Z 3} ; A f f_{36}=d_{1} / D_{o} ; L_{Z 1}=\left(L_{Z}-L_{Z 2}\right) / 2=L_{Z 3} ;$

$L_{A 1}=\left(L_{Z 1}-L_{C 1}\right) / 2=L_{B 1} ; L_{A 2}=\left(L_{Z 2}-L_{C 2}\right) / 2=L_{B 2} ;$

$L_{A 3}=\left(L_{Z 3}-L_{C 3}\right) / 2=L_{B 3} ; L_{1}=L_{2}=\left(L_{o}-L_{Z}\right) / 2$;

Likewise, the mean pressure drop $\left(\Delta p_{3}\right)$ of a three-chamber plug muffler is

$$
\begin{aligned}
\Delta p_{3}= & \mathrm{H}_{3 *}[(0.87+0.06 \times 1)+(0.87+0.06 \times 2) \\
& +(0.87+0.06 \times 3)]
\end{aligned}
$$

$\mathrm{H}_{3}=\rho V^{2} / 2 ; \mathrm{x} 1=4 L_{C 1} \eta_{1} / d_{1} ; \mathrm{x} 2=4 L_{C 2} \eta_{2} / d_{1} ; \mathrm{x} 3=4 L_{C 3} \eta_{3} / d_{1}$

To meet the system requirement of allowable maximal pressure drop $\left(\Delta p_{a}\right)$, the mean pressure drop $\left(\Delta p_{3}\right)$ should be governed as

$$
\left(\Delta p_{a}\right) \geq \Delta p_{3}
$$

\section{Objective Function}

By using the formulas of Eqs. (6), (16), and (28), the objective function used in the GA optimization with each type of plug muffler was established.

For a single-chamber muffler, the objective function in maximizing the STL at pure tone $(f)$ is

$$
\begin{aligned}
O B J_{1} & =\operatorname{STL}_{1}\left(Q, f, A f f_{11}, A f f_{12}, A f f_{13}, \eta_{1}, d h_{1}, \Delta p_{1}\right) \\
& =20 \log \left(\frac{\left|T_{11}^{*}+T_{12}^{*}+T_{21}^{*}+T_{22}^{*}\right|}{2}\right)+10 \log \left(\frac{S_{1}}{S_{3}}\right)
\end{aligned}
$$

where

$$
\begin{aligned}
& A f f_{11}=L_{Z} / L_{o} ; A f f_{12}=L_{C 1 A} / L_{Z} ; A f f_{13}=d_{1} / D_{o} ; \\
& L_{A 1}=\left(L_{Z}-L_{C 1}\right)=L_{B 1} ; L_{1}=L_{2}=\left(L_{o}-L_{Z}\right) / 2 ; \\
& \Delta p_{1}=\mathrm{H}_{1^{*}}(0.87+0.06 \times 1) ;\left(\Delta p_{a}\right) \geq \Delta p_{1}
\end{aligned}
$$

Similarly, for a double-chamber muffler, the objective function in maximizing the STL at pure tone $(f)$ is

$$
\begin{aligned}
O B J_{2}= & \operatorname{STL}_{2}\left(Q, f, A f f_{21}, A f f_{22}, A f f_{23}, A f f_{24}, A f f_{25}, \eta_{1}, d h_{1}, \eta_{2},\right. \\
& \left.d h_{2}, \Delta p_{2}\right) \\
= & 20 \log \left(\frac{\left|T_{11}^{*}+T_{12}^{*}+T_{21}^{*}+T_{22}^{*}\right|}{2}\right)+10 \log \left(\frac{S_{1}}{S_{5}}\right)
\end{aligned}
$$

where

$$
\begin{aligned}
& A f f_{21}=L_{Z} / L_{o} ; A f f_{22}=L_{Z 1} / L_{Z} ; A f f_{23}=L_{C 1} / L_{Z 1} ; A f f_{24}=L_{C 2} / L_{Z 2} ; \\
& A f f_{25}=d_{1} / D_{o} ; L_{Z 2}=L_{Z}-L_{Z 1} ; L_{A 1}=\left(L_{Z 1}-L_{C 1}\right) / 2=L_{B 1} ; \\
& L_{A 2}=\left(L_{Z 2}-L_{C 2}\right) / 2=L_{B 2} ; L_{1}=L_{2}=\left(L_{o}-L_{Z}\right) / 2 ; \\
& \Delta p_{2}=\mathrm{H}_{2 *}[(0.87+0.06 \times 1)+(0.87+0.06 \times 2)] ;\left(\Delta p_{a}\right) \geq \Delta p_{2}
\end{aligned}
$$

Equally, for a three-chamber muffler, the objective function in maximizing the STL at pure tone $(f)$ is

$$
\begin{aligned}
{O B J_{3}}_{3} & =\operatorname{STL}_{3}\left(\begin{array}{l}
Q, f, A f f_{31}, A f f_{32}, A f f_{33}, A f f_{34}, A f f_{35}, A f f_{36}, \\
\eta_{1}, d h_{1}, \eta_{2}, d h_{2}, \eta_{3}, d h_{3}, \Delta p_{3}
\end{array}\right) \\
& =20 \log \left(\frac{\left|T_{11}^{*}+T_{12}^{*}+T_{21}^{*}+T_{22}^{*}\right|}{2}\right)+10 \log \left(\frac{S_{1}}{S_{7}}\right)
\end{aligned}
$$

where

$$
\begin{aligned}
& A f f_{31}=L_{Z} / L_{o} ; A f f_{32}=L_{Z 2} / L_{Z} ; A f f_{33}=L_{C 1} / L_{Z 1} ; A f f_{34}=L_{C 2} / L_{Z 2} ; \\
& A_{f f_{35}}=L_{C 3} / L_{Z 3} ; A f f_{36}=d_{1} / D_{o} ; L_{Z 1}=\left(L_{Z}-L_{Z 2}\right) / 2=L_{Z 3} ; \\
& L_{A 1}=\left(L_{Z 1}-L_{C 1}\right) / 2=L_{B 1} ; L_{A 2}=\left(L_{Z 2}-L_{C 2}\right) / 2=L_{B 2} ; \\
& L_{A 3}=\left(L_{Z 3}-L_{C 3}\right) / 2=L_{B 3} ; L_{1}=L_{2}=\left(L_{o}-L_{Z}\right) / 2 ; \\
& \Delta p_{3}=\mathrm{H}_{3^{*}}[(0.87+0.06 \times 1)+(0.87+0.06 \times 2)+(0.87+0.06 \times 3)] ;
\end{aligned}
$$$$
\left(\Delta p_{a}\right) \geq \Delta p_{3}
$$ 

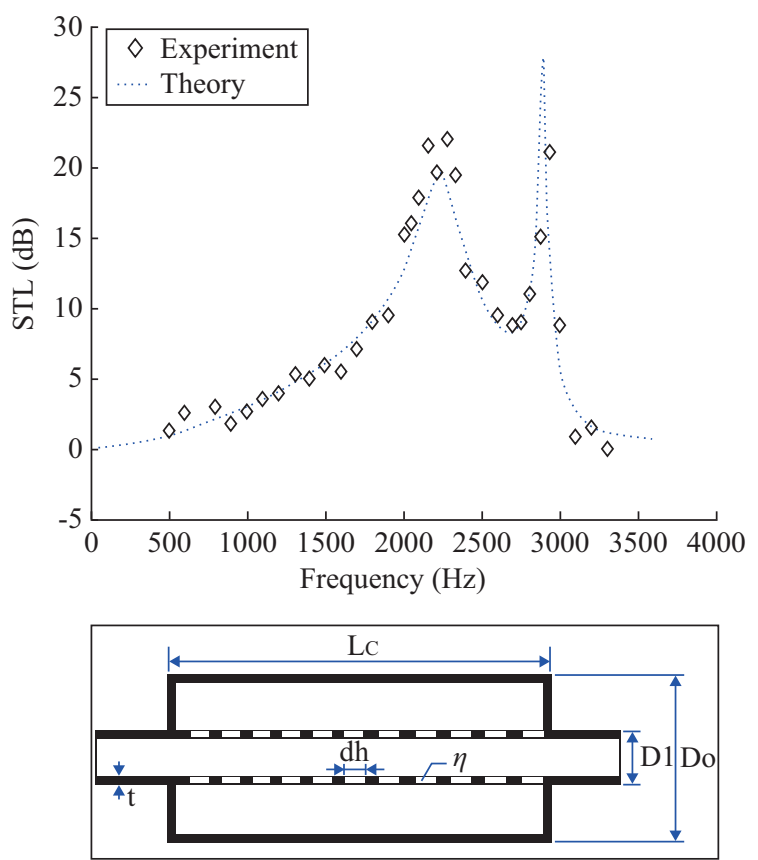

Fig. 4. The performance of a single-chamber perforated muffler without the mean flow $\left[D_{1}=0.058(\mathrm{~m}), D_{o}=0.0762(\mathrm{~m}), L_{c}=0.0667(\mathrm{~m})\right.$, $t=0.0081(\mathrm{~m}), d h=0.00249(\mathrm{~m}), \eta=0.037]$, [Experimental data is from Sullivan and Crocker [15]].

\section{MODEL CHECK}

Before performing the GA optimal simulation on mufflers, accuracy checks of the mathematical models on a singlechamber plug perforated muffler are performed using the experimental data from Sullivan [15]. As depicted in Fig. 4, the performance curves with respective to the theoretical and experimental data are in agreement. Based on plane wave theory, the proposed theoretical cutoff frequency of $f c_{1}$ $\left(f_{c 1}=\frac{1.84 c_{o}}{\pi D}\left(1-M^{2}\right)^{1 / 2}\right)$ is $2613 \mathrm{~Hz}$. Therefore, the proposed fundamental mathematical models with related acoustical components are acceptable. Consequently, the models linked with the numerical method are applied to the shape optimization in the following section.

\section{CASE STUDIES}

In this paper, a blower confined within a RC (reinforced concrete) room is shown in Fig. 1. As shown in Fig. 1, the available space for a muffler is $0.3 \mathrm{~m}$ in width, $0.3 \mathrm{~m}$ in height, and $1.5 \mathrm{~m}$ in length. In the existing venting system, the flow rate $(Q)$ and thickness of perforated tube $(t)$ are given as 0.05 $\left(\mathrm{m}^{3} / \mathrm{s}\right)$ and $0.0015(\mathrm{~m})$. To efficiently depress the tone noise under a specified pressure drop, the straight-type and multichamber perforated muffler is considered. To fully demonstrate good acoustical performance and design flexibility of the silencers, a series of targeted pure tones $(200,500 \mathrm{~Hz})$ for
Table 1. Range of design parameters for three kinds of multichamber perforated mufflers.

\begin{tabular}{|c|c|}
\hline Muffler Type & Range of design parameters \\
\hline One-Chamber & $\begin{array}{l}\text { Targeted } f:\{200,500\} ; Q=0.05\left(\mathrm{~m}^{3} / \mathrm{s}\right) ; D_{o}=0.3 \\
(\mathrm{~m}) ; L_{o}=1.5(\mathrm{~m}) ; \\
\text { Aff }_{11}:[0.5,0.9] ; A f f_{12}:[0.3,0.7] ; A f f_{13}:[0.1,0.9] ; \\
\eta_{1}:[0.03,0.1] ; d h_{1}:[0.00175,0.007] ; \Delta p_{a}: 600 \\
(\mathrm{~Pa})\end{array}$ \\
\hline Two-Chamber & $\begin{array}{l}\text { Targeted } f:\{200,500\} ; Q=0.05\left(\mathrm{~m}^{3} / \mathrm{s}\right) ; D_{o}=0.3 \\
(\mathrm{~m}) ; L_{o}=1.5(\mathrm{~m}) ; \\
\text { Aff }_{21}:[0.5,0.9] ; A_{f f}:[0.5,0.9] ; A f f_{23}:[0.5,0.9] ; \\
\text { Aff }_{24}:[0.5,0.9] ; \text { Aff }_{25}:[0.1,0.9] ; \eta_{1}:[0.03,0.1] ; \\
d h_{1}:[0.00175,0.007] ; \eta_{2}:[0.03,0.1] ; d h_{2}:[0.00175 \text {, } \\
0.007] ; \Delta p_{a}: 600(\mathrm{~Pa})\end{array}$ \\
\hline Three-Chamber & $\begin{array}{l}\text { Targeted } f:\{200,500\} ; Q=0.05\left(\mathrm{~m}^{3} / \mathrm{s}\right) ; D_{o}=0.3 \\
(\mathrm{~m}) ; \mathrm{Lo}=1.5(\mathrm{~m}) \\
\text { Aff }_{31}:[0.5,0.9] ; A f f_{32}:[0.5,0.9] ; A f f_{33}:[0.5,0.9] ; \\
\text { Aff }_{34}:[0.5,0.9] ; A f f_{35}:[0.5,0.9] ; A f_{36}:[0.1,0.9] ; \\
\eta_{1}:[0.03,0.1] ; d h_{1}:[0.00175,0.007] ; \eta_{2}:[0.03 \text {, } \\
0.1] ; d h_{2}:[0.00175,0.007] ; \eta_{3}:[0.03,0.1] ; d h_{3}: \\
{[0.00175,0.007] ; \Delta p_{a}: 600(\mathrm{~Pa})}\end{array}$ \\
\hline
\end{tabular}

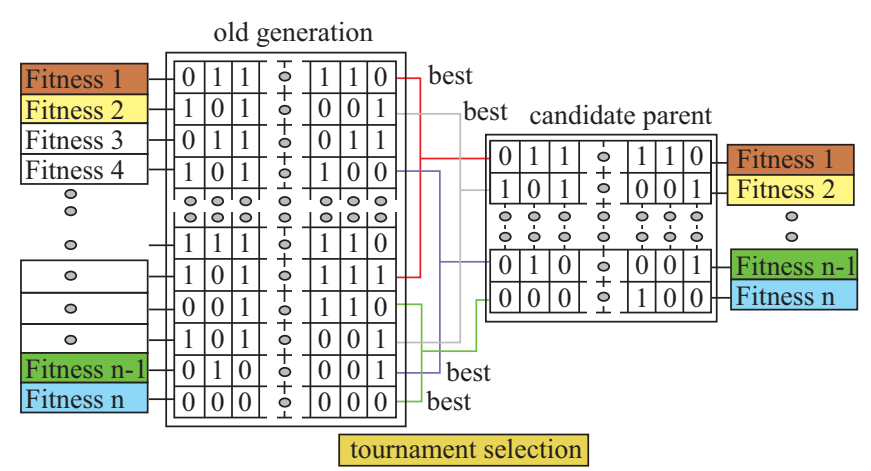

Fig. 5. The scheme of elitism by tournament selection.

noise elimination have been chosen. To prevent an overloaded back pressure which will slow down the preset volume-flowrate $(Q)$, the allowable maximal $\Delta p$ of $600(\mathrm{~Pa})$ in a muffler is specified in advance. The corresponding space constraints and the ranges of design parameters for each muffler are summarized in Table 1.

\section{GENETIC ALGORITHM}

The concept of Genetic Algorithms, first formalized by Holland [4] and extended to functional optimization by D. Jong [6], involves the use of optimal search strategies patterned after the Darwinian notion of natural selection. During a GA optimization, one set of trial solutions was chosen and "evolved" toward an optimal solution.

As the block diagram indicates in Fig. 5, GA accomplishes the task of optimization by starting with a random "population" of values for the parameters of an optimization problem. Afterwards, a new "generation" with an improved value of the 


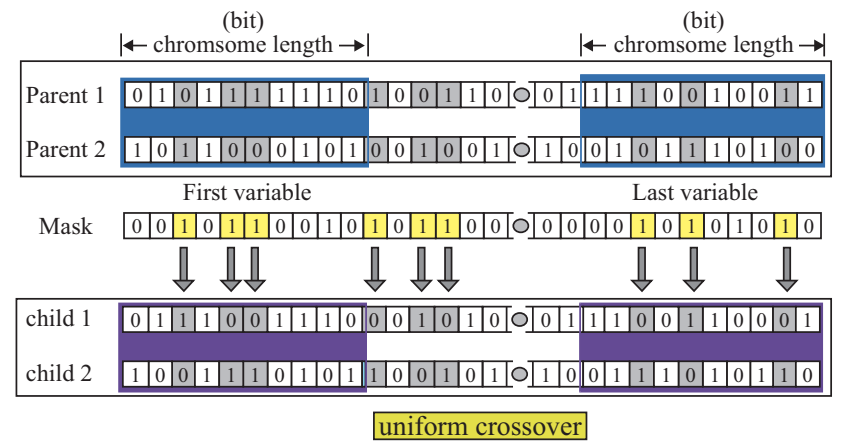

Fig. 6. The scheme of uniform crossover.

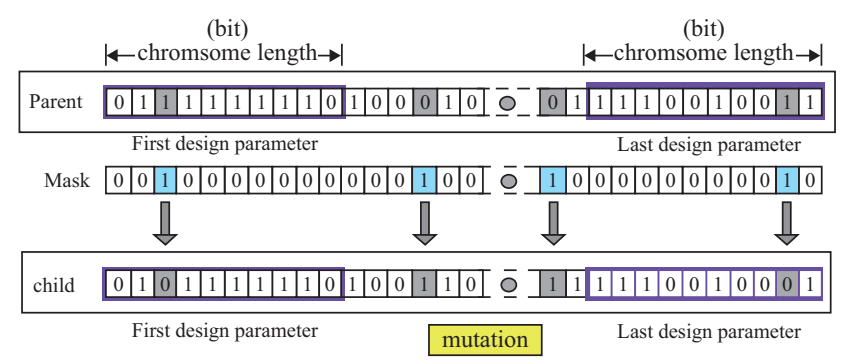

Fig. 7. The scheme of mutation.

objection function is produced. In order to achieve the evolution of a new generation, the binary system, a representation of real numbers and integers, is used. In addition, by manipulating the strings, the operators of reproduction, crossover, mutation, and elitism are initiated sequentially. As indicated in Fig. 6, to process the elitism of a gene, the tournament selection, a random comparison of the relative fitness from pairs of chromosomes, was applied.

During the GA optimization, one pair of offspring was generated from the selected parent by uniform crossover with a probability of $p c$. The applied mechanism of uniform crossover is depicted in Fig. 7. By using the masked genes randomly generated, the gene information between parents will be internally exchanged if the mapping gene is 1 .

Genetically, mutation occurred with a probability of $\mathrm{pm}$ where the new and unexpected point was brought into the GA optimizer's search domain. A typical scheme of mutation is depicted in Fig. 8. Likewise, by using masked genes randomly generated, the mapped gene will be converted from 1 to 0 , or from 0 to 1 , if the mapping gene is 1 .

To prevent the best gene from disappearing and to improve the accuracy of optimization during reproduction, the elitism scheme of keeping the best gene (one pair) in the parent generation with the tournament strategy was developed. The process was terminated when a number of generations exceeded a pre-selected value of iter $_{\max }$. The operations in the GA method are pictured in Fig. 9.

For the optimization of the objective function $(O B J)$, the design parameters of $\left(X_{1}, X_{2}, \ldots, X_{\mathrm{k}}\right)$ were determined. When the bit (the bit length of the chromosome) was chosen, the

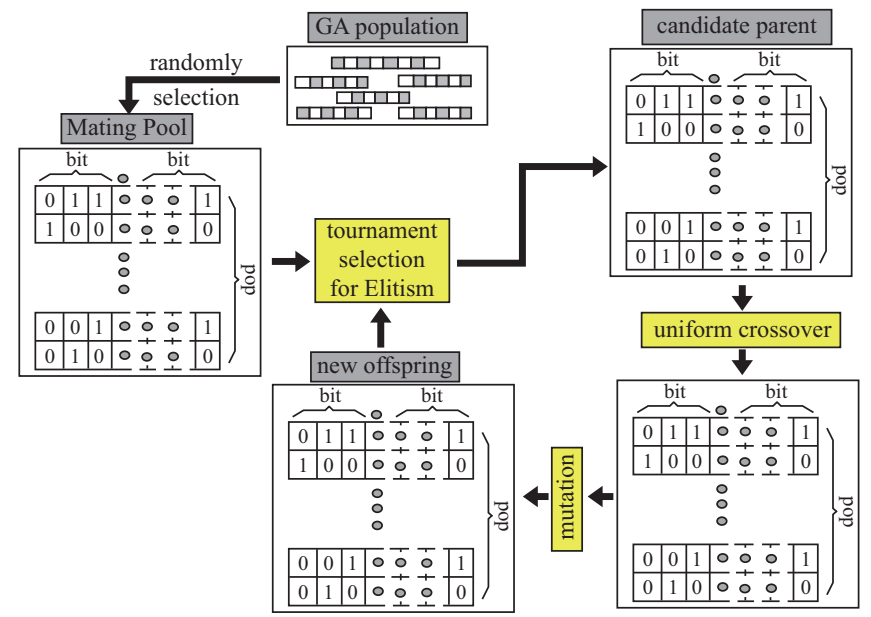

Fig. 8. The operations in the GA method.

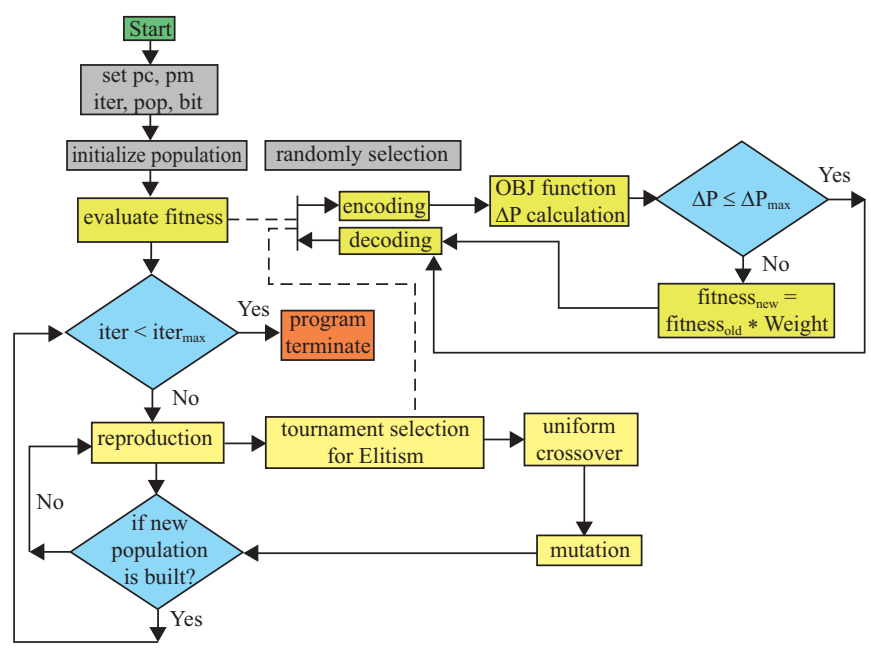

Fig. 9. The block diagram of the GA optimization on mufflers.

interval of the design parameter $\left(X_{k}\right)$ with $[L b, U b]_{k}$ was mapped to the band of the binary value. The mapping system between the variable interval of $[L b, U b]_{k}$ and the $k^{\text {th }}$ binary chromosome of

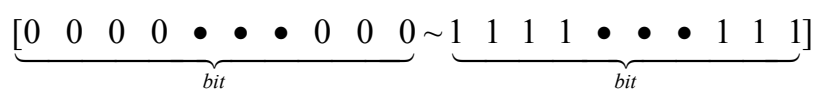

was constructed. The encoding from $x$ to $B 2 D$ (binary to decimal) can be performed as

$$
B 2 D_{k}=\text { integer }\left\{\frac{x_{k}-L b_{k}}{U b_{k}-L b_{k}}\left(2^{b i t}-1\right)\right\}
$$

The initial population was built up by randomization. The parameter set was encoded to form a string which represented the chromosome. By evaluating the objective function $(O B J)$, the whole set of chromosomes $\left[B 2 D_{1}, B 2 D_{2}, \ldots ., B 2 D_{k}\right]$ that 
changed from binary form to decimal form was assigned a fitness by decoding the transformation system:

$$
\text { fitness }=O B J\left(X_{1}, X_{2}, \ldots, X_{k}\right) \text {; }
$$

where

$$
X_{k}=B 2 D_{k} *\left(U b_{k}-L b_{k}\right) /\left(2^{b i t}-1\right)+L b_{k}
$$

For three kinds of mufflers, to simplify the optimization, the flow rate $\left(Q=0.05\left(\mathrm{~m}^{3} / \mathrm{s}\right)\right)$ and thickness of the perforated tube $\left(t_{1}=t_{2}=0.0081(\mathrm{~m})\right)$ are preset in advance; therefore, Eqs. (31-33), the objective functions $O B J_{1}, O B J_{2}$, and $O B J_{3}$ and their ranges, are reduced and set as

$$
O B J_{1}=\operatorname{STL}_{1}\left(A f f_{11}, A f f_{12}, A f f_{13}, \eta_{1}, d h_{1}\right)
$$

where

$$
\begin{gathered}
A f f_{11}=L_{Z} / L_{o} ; A f f_{12}=L_{C 1 A} / L_{Z} ; A f f_{13}=d_{1} / D_{o} ; \\
L_{A 1}=\left(L_{Z}-L_{C 1}\right)=L_{B 1} ; L_{1}=L_{2}=\left(L_{o}-L_{Z}\right) / 2 \\
O B J_{2}=\operatorname{STL}_{2}\left(A f f_{21}, A f f_{22}, A f f_{23}, A f f_{24}, A f f_{25}, \eta_{1}, d h_{1}, \eta_{2}, d h_{2}\right)
\end{gathered}
$$

where

$A f f_{21}=L_{Z} / L_{o} ; A f f_{22}=L_{Z 1} / L_{Z} ; A f f_{23}=L_{C 1} / L_{Z 1} ; A f f_{24}=L_{C 2} / L_{Z 2} ;$

$A f f_{25}=d_{1} / D_{o} ; L_{Z 2}=L_{Z}-L_{Z 1} ; L_{A 1}=\left(L_{Z 1}-L_{C 1}\right) / 2=L_{B 1} ;$

$L_{A 2}=\left(L_{Z 2}-L_{C 2}\right) / 2=L_{B 2} ; L_{1}=L_{2}=\left(L_{o}-L_{Z}\right) / 2$

$$
O B J_{3}=\operatorname{STL}_{3}\left(\begin{array}{l}
A f f_{31}, A f f_{32}, A f f_{33}, A f f_{34}, A f f_{35}, \\
A f f_{36}, \eta_{1}, d h_{1}, \eta_{2}, d h_{2}, \eta_{3}, d h_{3}
\end{array}\right)
$$

where

$A f f_{31}=L_{Z} / L_{o} ; A f f_{32}=L_{Z 2} / L_{Z} ; A f f_{33}=L_{C 1} / L_{Z 1} ; A f f_{34}=L_{C 2} / L_{Z 2} ;$

$A f f_{35}=L_{C 3} / L_{Z 3} ; A f f_{36}=d_{1} / D_{o} ; L_{Z 1}=\left(L_{Z}-L_{Z 2}\right) / 2=L_{Z 3} ;$

$L_{A 1}=\left(L_{Z 1}-L_{C 1}\right) / 2=L_{B 1} ; L_{A 2}=\left(L_{Z 2}-L_{C 2}\right) / 2=L_{B 2} ;$

$L_{A 3}=\left(L_{Z 3}-L_{C 3}\right) / 2=L_{B 3} ; L_{1}=L_{2}=\left(L_{o}-L_{Z}\right) / 2$

As indicated in Fig. 9, to meet the specified back-pressure $(\Delta p)$, the back pressure $(\Delta p)$ will be calculated and compared

\begin{tabular}{|c|c|c|c|c|c|c|c|c|c|}
\hline Item & \multicolumn{5}{|c|}{ GA parameters } & \multicolumn{4}{|c|}{ Results } \\
\hline \multirow{4}{*}{1} & \multirow{2}{*}{ рор } & \multirow{2}{*}{ bit } & \multirow{2}{*}{ pm } & \multirow[b]{2}{*}{$p c$} & \multirow{2}{*}{ iter $_{\max }$} & $A f f_{11}$ & $A f f_{12}$ & $A f f_{13}$ & STL (dB) \\
\hline & & & & & & 0.9000 & 0.5004 & 0.2783 & 45.934 \\
\hline & \multirow{2}{*}{40} & \multirow{2}{*}{10} & \multirow{2}{*}{0.02} & \multirow{2}{*}{0.3} & \multirow{2}{*}{50} & $\eta_{1}$ & $d h_{1}(\mathrm{~m})$ & & $\Delta p(\mathrm{~Pa})$ \\
\hline & & & & & & 0.0300 & 0.0051 & & 92.9 \\
\hline \multirow{4}{*}{2} & & & & & & $A f f_{11}$ & $A f f_{12}$ & $A f f_{13}$ & STL (dB) \\
\hline & pop & but & $p m$ & $p c$ & iter $\max$ & 0.9000 & 0.5000 & 0.2501 & 47.737 \\
\hline & 40 & 10 & בחת & 06 & 50 & $\eta_{1}$ & $d h_{1}(\mathrm{~m})$ & & $\Delta p(\mathrm{~Pa})$ \\
\hline & 40 & 10 & 0.02 & 0.0 & 50 & 0.0300 & 0.0051 & & 143.4 \\
\hline & & hit & & & & $A f f_{11}$ & $A f f_{12}$ & $A f f_{13}$ & STL (dB) \\
\hline 3 & pop & DIt & $p m$ & $p c$ & $\| t e r_{\max }$ & 0.9000 & 0.5000 & 0.2001 & 52.726 \\
\hline 3 & 40 & 10 & בח02 & 09 & 50 & $\eta_{1}$ & $d h_{1}(\mathrm{~m})$ & & $\Delta p(\mathrm{~Pa})$ \\
\hline & 40 & 10 & 0.02 & $\underline{0.9}$ & 50 & 0.0300 & 0.0024 & & 356.1 \\
\hline & & hit & & & & $A f f_{11}$ & $A f f_{12}$ & $A f f_{13}$ & STL (dB) \\
\hline 4 & pop & Dit & $p m$ & $p c$ & iter $\max$ & 0.9000 & 0.5000 & 0.1782 & 56.857 \\
\hline 4 & & & & & & $\eta_{1}$ & $d h_{1}(\mathrm{~m})$ & & $\Delta p(\mathrm{~Pa})$ \\
\hline & 40 & 10 & $\underline{0.05}$ & $\underline{0.9}$ & 50 & 0.0300 & 0.0051 & & 572.1 \\
\hline & & hit & & & iter & $A f f_{11}$ & $A f f_{12}$ & $A f f_{13}$ & STL (dB) \\
\hline 5 & $p o p$ & Dil & $p m$ & $p c$ & $\| l e r_{\max }$ & 0.9000 & 0.5000 & 0.1782 & 58.850 \\
\hline & 40 & 10 & 008 & 00 & 50 & $\eta_{1}$ & $d h_{1}(\mathrm{~m})$ & & $\Delta p(\mathrm{~Pa})$ \\
\hline & 40 & 10 & 0.08 & 0.9 & 50 & 0.0300 & 0.0024 & & 572.1 \\
\hline & & hit & & & & $A f f_{11}$ & $A f f_{12}$ & $A f f_{13}$ & STL (dB) \\
\hline 6 & pop & but & $p m$ & $p c$ & iter $\max$ & 0.8984 & 0.5000 & 0.2001 & 52.453 \\
\hline 6 & 40 & 15 & 005 & 00 & 50 & $\eta_{1}$ & $d h_{1}(\mathrm{~m})$ & & $\Delta p(\mathrm{~Pa})$ \\
\hline & 40 & 15 & $\underline{0.05}$ & $\underline{0.9}$ & 50 & 0.0302 & 0.0035 & & 356.2 \\
\hline & & & & & & $A f f_{11}$ & $A f f_{12}$ & $A f f_{13}$ & STL (dB) \\
\hline 7 & pop & but & $p m$ & $p c$ & iter $\max$ & 0.8982 & 0.5000 & 0.1766 & 59.080 \\
\hline f & 40 & 20 & 005 & 00 & 50 & $\eta_{1}$ & $d h_{1}(\mathrm{~m})$ & & $\Delta p(\mathrm{~Pa})$ \\
\hline & 40 & $\underline{20}$ & $\underline{0.05}$ & 0.9 & 50 & 0.0311 & 0.0020 & & 595.6 \\
\hline & & hit & & & & $A f f_{11}$ & $A f f_{12}$ & $A f f_{13}$ & STL (dB) \\
\hline 8 & pop & Dit & $p m$ & $p c$ & iter $\max$ & 0.8998 & 0.5004 & 0.1770 & 58.507 \\
\hline 8 & 40 & 25 & 005 & 00 & 50 & $\eta_{1}$ & $d h_{1}(\mathrm{~m})$ & & $\Delta p(\mathrm{~Pa})$ \\
\hline & 40 & 25 & $\underline{0.05}$ & $\underline{0.9}$ & 50 & 0.0300 & 0.0031 & & 588.2 \\
\hline & non & hit & $n m$ & $n c$ & & $A f f_{11}$ & $A f f_{12}$ & $A f f_{13}$ & STL (dB) \\
\hline 9 & $p o p$ & Dil & $p m$ & $p c$ & tler max & 0.8934 & 0.5000 & 0.2003 & 52.165 \\
\hline & 40 & 30 & 005 & 09 & 50 & $\eta_{1}$ & $d h_{1}(\mathrm{~m})$ & & $\Delta p(\mathrm{~Pa})$ \\
\hline & 40 & 30 & $\underline{0.05}$ & $\underline{0.9}$ & 50 & 0.0304 & 0.0018 & & 354.8 \\
\hline & non & hit & $n m$ & $n c$ & & $A f f_{11}$ & $A f f_{12}$ & $A f f_{13}$ & STL (dB) \\
\hline 10 & pop & Dlt & $p m$ & $p c$ & iter $\max$ & 0.8992 & 0.5000 & 0.1781 & 58.563 \\
\hline & 60 & 20 & 005 & 00 & 50 & $\eta_{1}$ & $d h_{1}(\mathrm{~m})$ & & $\Delta p(\mathrm{~Pa})$ \\
\hline & & $\underline{20}$ & $\underline{0.05}$ & 0.9 & 50 & 0.0312 & 0.0018 & & 575.5 \\
\hline & non & hit & $\mathrm{nm}$ & $n c$ & iter & $A f f_{11}$ & $A f f_{12}$ & $A f f_{13}$ & STL (dB) \\
\hline 11 & pop & & $p m$ & $p c$ & $\| t e r_{\text {max }}$ & 0.8992 & 0.5004 & 0.1763 & 59.570 \\
\hline 11 & 80 & 20 & 005 & 09 & 50 & $\eta_{1}$ & $d h_{1}(\mathrm{~m})$ & & $\Delta p(\mathrm{~Pa})$ \\
\hline & $\underline{80}$ & $\underline{20}$ & $\underline{0.05}$ & 0.9 & 50 & 0.0303 & 0.0021 & & 598.3 \\
\hline & & hit & & & & $A f f_{11}$ & $A f f_{12}$ & $A f f_{13}$ & STL (dB) \\
\hline 12 & pop & but & pm & $p c$ & iter $r_{\max }$ & 0.8999 & 0.5004 & 0.2000 & 52.694 \\
\hline 12 & 100 & 20 & 005 & 0 & 50 & $\eta_{1}$ & $d h_{1}(\mathrm{~m})$ & & $\Delta p(\mathrm{~Pa})$ \\
\hline & & $\underline{20}$ & $\underline{0.05}$ & $\underline{0.9}$ & & 0.0300 & 0.0019 & & 356.8 \\
\hline & & hit & & & & $A f f_{11}$ & $A f f_{12}$ & $A f f_{13}$ & STL (dB) \\
\hline 13 & pop & Dit & $p m$ & $p c$ & iter $\max$ & 0.9000 & 0.5000 & 0.2000 & 52.795 \\
\hline 15 & 120 & 20 & 005 & 09 & 50 & $\eta_{1}$ & $d h_{1}(\mathrm{~m})$ & & $\Delta p(\mathrm{~Pa})$ \\
\hline & & & & & & 0.0300 & 0.0018 & & 356.8 \\
\hline & & hit & & & & $A f f_{11}$ & $A f f_{12}$ & $A f f_{13}$ & STL (dB) \\
\hline 14 & pop & bit & $p m$ & $p c$ & iter $_{\max }$ & 0.9000 & 0.5000 & 0.1763 & 60.432 \\
\hline & 80 & 20 & 005 & 09 & 100 & $\eta_{1}$ & $d h_{1}(\mathrm{~m})$ & & $\Delta p(\mathrm{~Pa})$ \\
\hline & & $\underline{20}$ & 0.05 & 0.9 & 100 & 0.0300 & 0.0018 & & 597.8 \\
\hline & & hit & & & & $A f f_{11}$ & $A f f_{12}$ & $A f f_{13}$ & STL (dB) \\
\hline 15 & pop & bit & $p m$ & $p c$ & iter $\max$ & \begin{tabular}{|l|}
0.9000 \\
\end{tabular} & 0.5000 & 0.1762 & 60.511 \\
\hline 10 & 80 & 20 & 0.5 & 09 & 200 & $\eta_{1}$ & $d h_{1}(\mathrm{~m})$ & & $\Delta p(\mathrm{~Pa})$ \\
\hline & $\underline{80}$ & $\underline{20}$ & $\underline{0.05}$ & $\underline{0.9}$ & $\underline{200}$ & 0.0300 & \begin{tabular}{|l|}
0.0018 \\
\end{tabular} & & 599.2 \\
\hline
\end{tabular}
with the limit of $\Delta p_{a}$ during the GA optimization. If $\Delta p$ is smaller than $\Delta p_{a}$, the current offspring will be valid and used for further evolution; otherwise, the fitness will be multiplied by 0.1 to discard the current gene.
Table 2. Optimal STLs for a one-chamber perforated muffler (targeted frequency: $200 \mathrm{~Hz}$ ). 


\section{RESULTS AND DISCUSSION}

\section{Results}

To achieve a proper optimization, five kinds of GA parameters, including population size ( $p o p)$, chromosome length (bit), maximum generation $\left(\right.$ iter $\left._{\max }\right)$, crossover ratio $(p c)$, and mutation ratio $(\mathrm{pm})$ are varied step by step during optimization. To appreciate the compromise between the acoustical performance and the back pressure during the mufflers optimization, the shape optimization along with the back-pressure's constraint and non-constraint conditions will be carried out simultaneously. The optimization system is encoded by Fortran and made to run on an IBM PC - Pentium IV. The optimal results in dealing with pure tone noises occurring in a blower room are described below.

\section{1) Back-Pressure Constraint}

\section{A. A One-Chamber Muffler}

For a one-chamber muffler, fifteen sets of GA parameters are tested by varying the values of the GA parameters. Concerning the pressure-drop constraint $(600(\mathrm{~Pa}))$, the simulated results of the pure tone $200 \mathrm{~Hz}$ are summarized in Table 2. As indicated in Table 2, the optimal design data can be obtained from the last set of GA parameters at (pop, bit, iter ${ }_{\max }, p c$, $p m)=(80,20,200,0.6,0.05)$. By calculating these design data sets, the related performance curves with respect to different GA parameters are plotted in Figs. 10 12. Obviously, the GA parameters - pop, bit, iter $_{\max }, p c, p m$ - play essential roles during numerical optimization. The above GA parameter set will be adopted in other cases during GA optimization. The resultant optimal acoustical performance curves of two targeted pure tones $(200,500 \mathrm{~Hz})$ are summarized in Table 3 and plotted in Fig. 13. As revealed in Table 3 and Fig. 13, the STLs are precisely maximized at the desired frequencies (200 $\mathrm{Hz}$ and $500 \mathrm{~Hz}$ ) with 60.5 and $58.3 \mathrm{~dB}$. Additionally, the predicted back pressures of the mufflers with 599.2 and 449.4 $(\mathrm{Pa})$ are under the specified $600(\mathrm{~Pa})$.

B. A Two-Chamber Muffler

For a two-chamber perforated muffler, the simulated results with respect to the pure tone of $200 \mathrm{~Hz}$ and $500 \mathrm{~Hz}$ are summarized in Table 4 and plotted in Fig. 14. As indicated in Table 4 and Fig. 14, the STLs are also precisely maximized at the desired frequencies $(200 \mathrm{~Hz}$ and $500 \mathrm{~Hz})$ with 46.3 and $111.5 \mathrm{~dB}$. Moreover, the predicted back pressure of the mufflers with 595.0 and $575.1(\mathrm{~Pa})$ can meet the requirement of the constrained value $\left(\Delta p_{a} 600(\mathrm{~Pa})\right)$.

\section{A Three-Chamber Muffler}

For a three-chamber perforated muffler, the simulated results of the pure tones $200 \mathrm{~Hz}$ and $500 \mathrm{~Hz}$ are summarized in Table 5 and plotted in Fig. 15. Obviously, the STLs are exactly maximized at the desired frequencies $(200 \mathrm{~Hz}$ and 500 $\mathrm{Hz}$ ) with 55.8 and $97.1 \mathrm{~dB}$. Also note, the predicted back pressures of mufflers with 576.3 and $599.1(\mathrm{~Pa})$ are under the constrained value of $\Delta p_{a}=600(\mathrm{~Pa})$.

Consequently, the resultant optimal acoustical performance

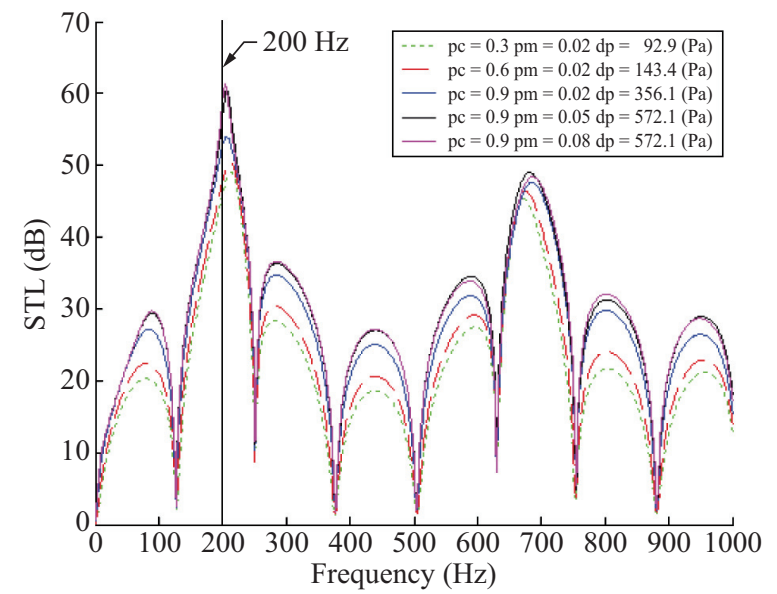

Fig. 10. STL curves with respect to various pc and pm [a one-chamber perforated muffler: $p o p=40$, bit $=10$, iter $=50, \Delta p_{a}=600(\mathrm{~Pa})$, targeted frequency $=\mathbf{2 0 0}(\mathrm{Hz})]$.

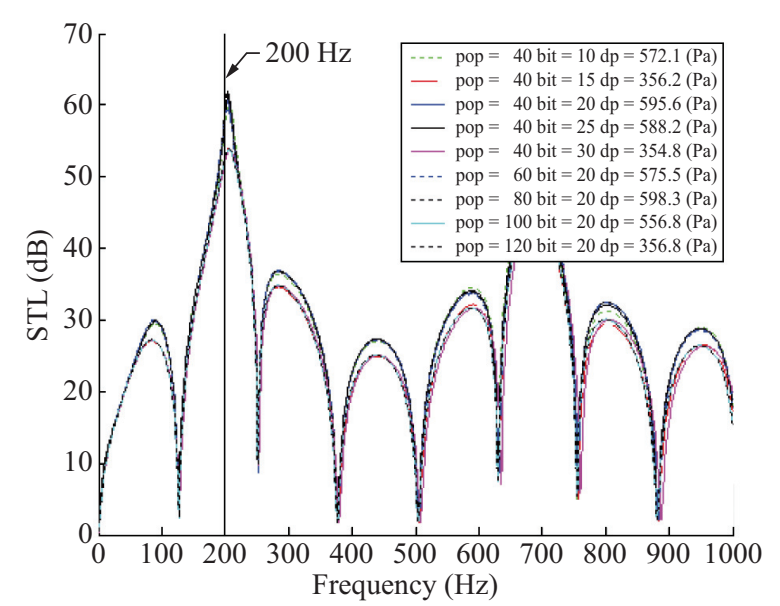

Fig. 11. STL curves with respect to various pop and bit [a one-chamber perforated muffler: $p c=0.9, p m=0.05$, iter $=50, \Delta p_{a}=600(\mathrm{~Pa})$, targeted frequency $=200(\mathrm{~Hz})]$.

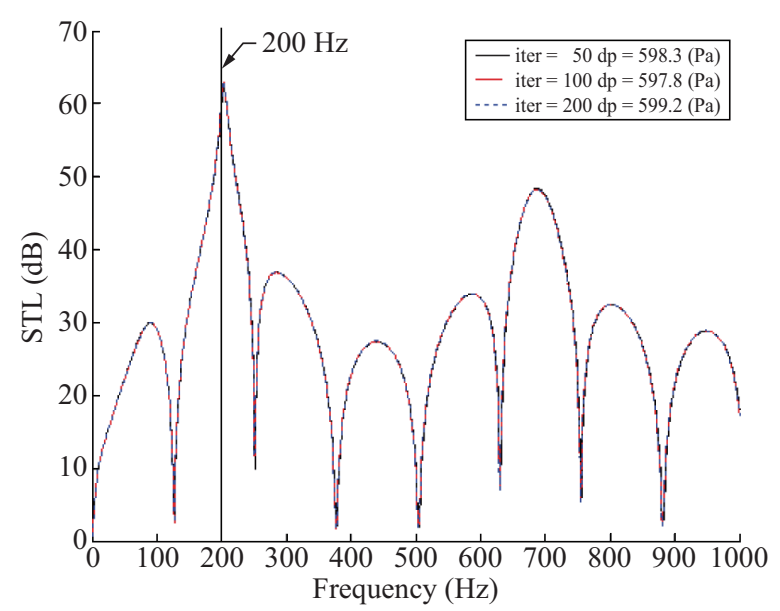

Fig. 12. STL curves with respect to various iter [a one-chamber perforated muffler: $p o p=80$, bit $=20, p c=0.9, p m=0.05, \Delta p_{a}=600$ $(\mathrm{Pa})$, targeted frequency $=200(\mathrm{~Hz})]$. 
Table 3. Optimal STLs for a one-chamber perforated muffler with respect to various targeted frequency (with $\Delta p$ constrain).

\begin{tabular}{|c|c|c|c|c|c|}
\hline \multirow{2}{*}{ Item } & Targeted & \multicolumn{4}{|c|}{ Results } \\
frequency & \multicolumn{4}{|c|}{} \\
\hline \multirow{3}{*}{1} & \multirow{3}{*}{$200 \mathrm{~Hz}$} & $A f f_{11}$ & $A f f_{12}$ & $A f f_{13}$ & STL (dB) \\
\cline { 3 - 6 } & & 0.9000 & 0.5000 & 0.1762 & 60.511 \\
\cline { 3 - 6 } & & $\eta_{1}$ & $d h_{1}(\mathrm{~m})$ & & $\Delta p(\mathrm{~Pa})$ \\
\cline { 3 - 6 } 2 & 0.0300 & 0.0018 & & 599.2 \\
\hline \multirow{3}{*}{2} & \multirow{3}{*}{$500 \mathrm{~Hz}$} & 0.7826 & 0.7499 & 0.2009 & 58.285 \\
\cline { 3 - 6 } & & $\eta_{1}$ & $d h_{1}(\mathrm{~m})$ & & $\Delta p(\mathrm{~Pa})$ \\
\cline { 3 - 6 } & & 0.0997 & 0.0070 & & 449.4 \\
\hline
\end{tabular}

Table 4. Optimal STLs for a two-chamber perforated muffler with respect to various targeted frequency (with $\Delta p$ constrain).

\begin{tabular}{|c|c|c|c|c|c|}
\hline Item & $\begin{array}{l}\text { Targeted } \\
\text { frequency }\end{array}$ & \multicolumn{4}{|c|}{ Results } \\
\hline \multirow{6}{*}{1} & \multirow{6}{*}{$200 \mathrm{~Hz}$} & $A f f_{21}$ & $A f f_{22}$ & $A f f_{23}$ & STL (dB) \\
\hline & & 0.7980 & 0.5001 & 0.6635 & 46.277 \\
\hline & & $A f f_{24}$ & Aff $_{25}$ & $\eta_{1}$ & $\Delta p(\mathrm{~Pa})$ \\
\hline & & 0.5010 & 0.2079 & 0.0307 & 595.0 \\
\hline & & $d h_{1}(\mathrm{~m})$ & $\eta_{2}$ & $d h_{2}(\mathrm{~m})$ & \\
\hline & & 0.0018 & 0.0559 & 0.0018 & \\
\hline \multirow{6}{*}{2} & \multirow{6}{*}{$500 \mathrm{~Hz}$} & $A f f_{21}$ & $A f f_{22}$ & $A f f_{23}$ & STL (dB) \\
\hline & & 0.7687 & 0.5000 & 0.5000 & 111.477 \\
\hline & & $A f f_{24}$ & $A f f_{25}$ & $\eta_{1}$ & $\Delta p(\mathrm{~Pa})$ \\
\hline & & 0.5000 & 0.2126 & 0.1000 & 575.1 \\
\hline & & $d h_{1}(\mathrm{~m})$ & $\eta_{2}$ & $d h_{2}(\mathrm{~m})$ & \\
\hline & & 0.0070 & 0.0999 & 0.0070 & \\
\hline
\end{tabular}

Table 5. Optimal STLs for a three-chamber perforated muffler with respect to various targeted frequency (with $\Delta p$ constrain).

\begin{tabular}{|c|c|c|c|c|c|}
\hline Item & $\begin{array}{l}\text { Targeted } \\
\text { frequency }\end{array}$ & \multicolumn{4}{|c|}{ Results } \\
\hline \multirow{8}{*}{1} & \multirow{8}{*}{$200 \mathrm{~Hz}$} & $A f f_{31}$ & $A f f_{32}$ & $A f f_{33}$ & STL (dB) \\
\hline & & 0.9000 & 0.5000 & 0.9000 & 55.822 \\
\hline & & $A f f_{34}$ & $A f f_{35}$ & $A f f_{36}$ & $\Delta p(\mathrm{~Pa})$ \\
\hline & & 0.5254 & 0.9000 & 0.2313 & 576.3 \\
\hline & & $\eta_{1}$ & $d h_{1}(\mathrm{~m})$ & $\eta_{2}$ & \\
\hline & & 0.0481 & 0.0018 & 0.0300 & \\
\hline & & $d h_{2}(\mathrm{~m})$ & $\eta_{3}$ & $d h_{3}(\mathrm{~m})$ & \\
\hline & & 0.0018 & 0.0478 & 0.0018 & \\
\hline \multirow{8}{*}{2} & \multirow{8}{*}{$500 \mathrm{~Hz}$} & $A f f_{31}$ & $A f f_{32}$ & $A f f_{33}$ & STL (dB) \\
\hline & & 0.6982 & 0.5502 & 0.7142 & 97.149 \\
\hline & & $A f f_{34}$ & $A f f_{35}$ & $A f f_{36}$ & $\Delta p(\mathrm{~Pa})$ \\
\hline & & 0.5001 & 0.7030 & 0.2295 & 599.1 \\
\hline & & $\eta_{1}$ & $d h_{1}(\mathrm{~m})$ & $\eta_{2}$ & \\
\hline & & 0.0501 & 0.0066 & 0.0999 & \\
\hline & & $d h_{2}(\mathrm{~m})$ & $\eta_{3}$ & $d h_{3}(\mathrm{~m})$ & \\
\hline & & 0.0070 & 0.0495 & 0.0070 & \\
\hline
\end{tabular}

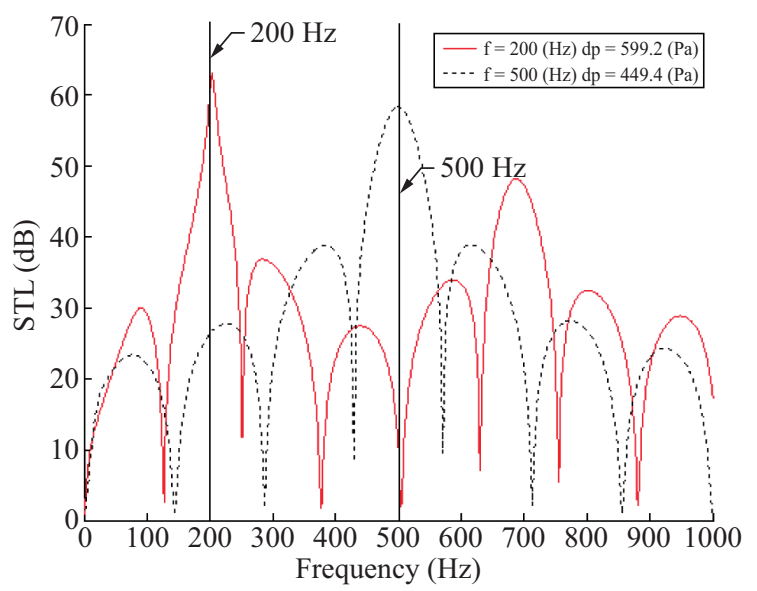

Fig. 13. STL curves with respect to various targeted frequencies [a onechamber perforated muffler: targeted frequency $=200,500(\mathrm{~Hz})$, $\left.\Delta p_{a}=600(\mathrm{~Pa})\right]$.

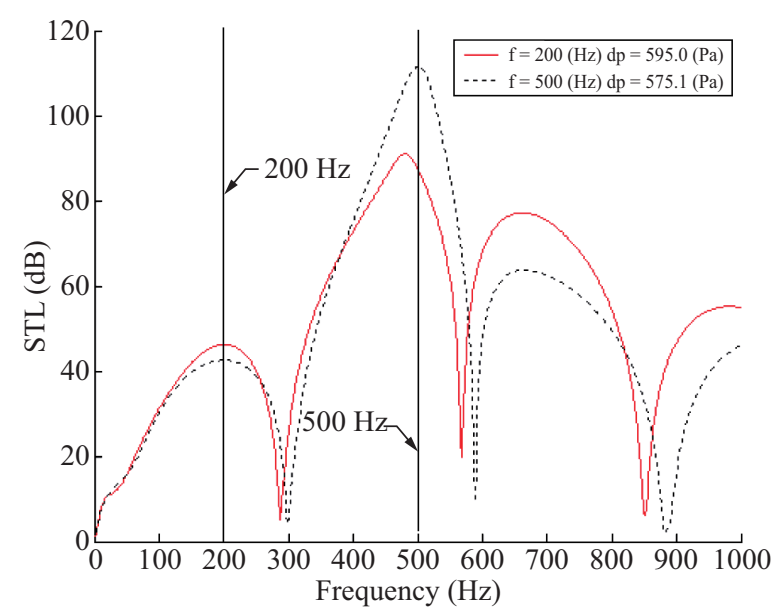

Fig. 14. STL curves with respect to various targeted frequencies [a twochamber perforated muffler: targeted frequency $=200,500(\mathrm{~Hz})$, $\left.\Delta p_{a}=600(\mathrm{~Pa})\right]$.

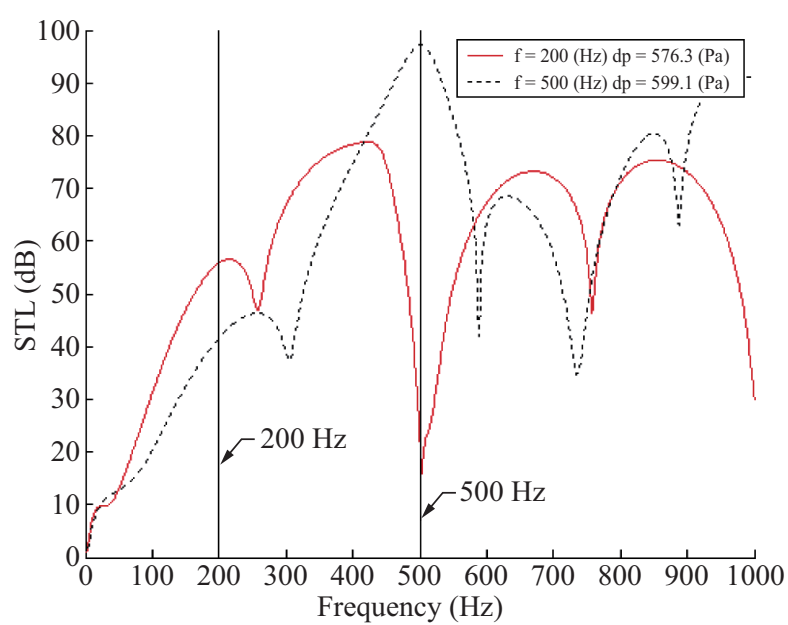

Fig. 15. STL curves with respect to various targeted frequencies [a threechamber perforated muffler: targeted frequency $=200,500(\mathrm{~Hz})$, $\left.\Delta p_{a}=600(\mathrm{~Pa})\right]$. 


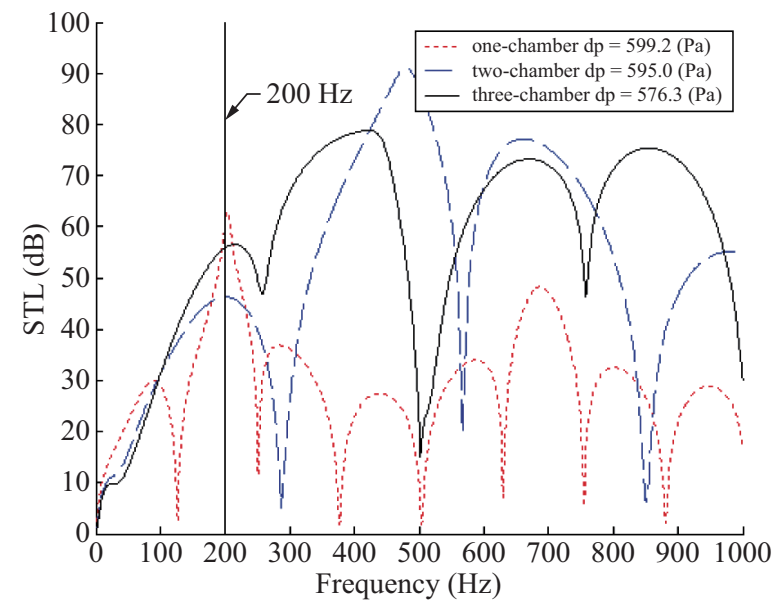

Fig. 16. STL curves with respect to three kinds of mufflers with backpressure constraint [targeted frequency $=\mathbf{2 0 0}(\mathrm{Hz})]$

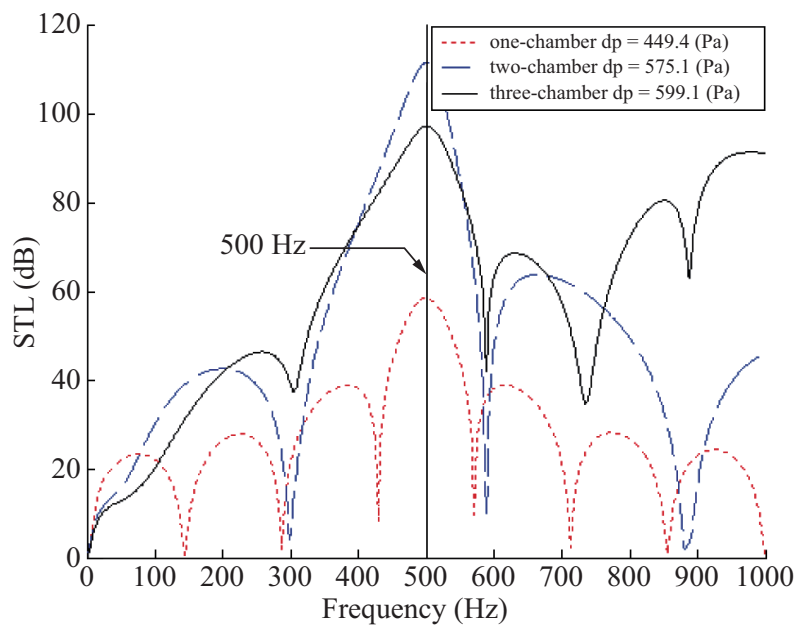

Fig. 17. STL curves with respect to three kinds of mufflers with backpressure constraint [targeted frequency $=\mathbf{5 0 0}(\mathrm{Hz})]$.

curves of three kinds of multi-chamber perforated mufflers (a one-chamber, two-chamber, and a three-chamber muffler) at the targeted frequencies $(200,500 \mathrm{~Hz})$ are summarized and plotted in Figs. 16 and 17, where the back pressure is 449 599 $(\mathrm{Pa})$. As indicated in Figs. 16 and 17, because of the backpressure limit, the chambers have lent no improvement to the acoustical performance.

\section{2) Back-Pressure Non-Constraint}

By using the above GA parameter set and discarding the back-pressure constraint, the optimal acoustical performance curves with respect to three kinds of perforated mufflers at various targeted tones $(200,500 \mathrm{~Hz})$ are obtained and plotted in Figs. 18 and 19. As indicated in Figs. 18 19, it is obvious that the STLs at the targeted frequencies will be improved when the number of chambers in the mufflers is increased. Note, the back-pressure in the mufflers will be increased to 1332 16655 $(\mathrm{Pa})$, which is far beyond the specified value of $600(\mathrm{~Pa})$.

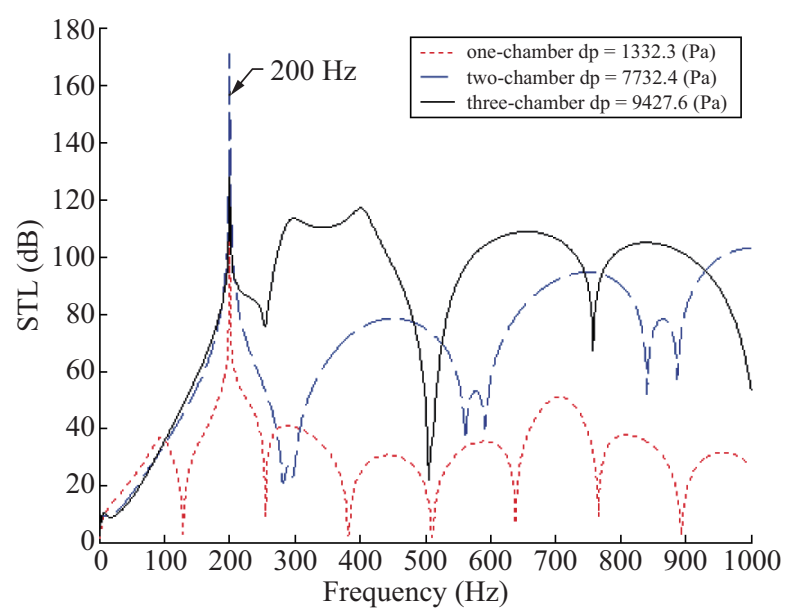

Fig. 18. STL curves with respect to three kinds of mufflers without backpressure constraint [targeted frequency $=200(\mathrm{~Hz})]$.

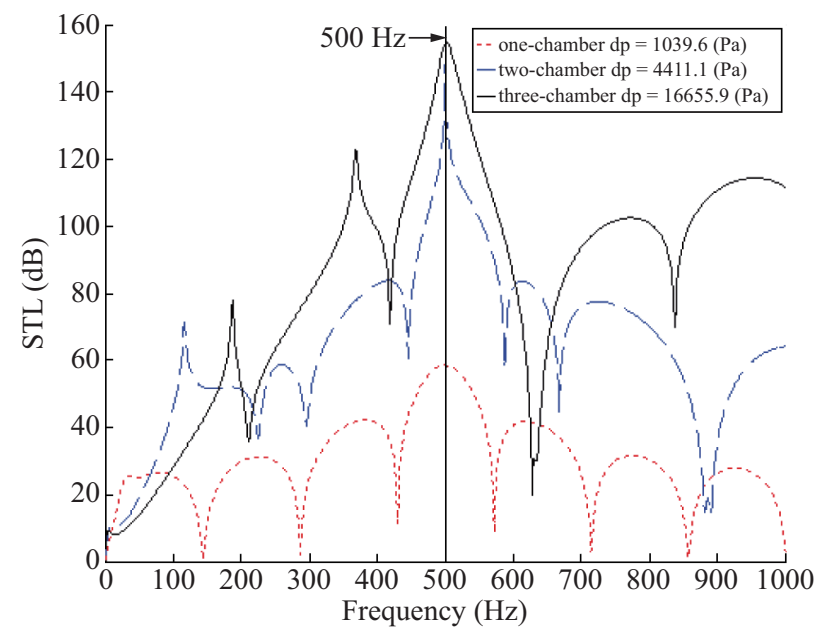

Fig. 19. STL curves with respect to three kinds of mufflers without backpressure constraint $[$ targeted frequency $=\mathbf{5 0 0}(\mathrm{Hz})]$.

\section{Discussion}

To appreciate the acoustical performance of three kinds of mufflers when the specified back-pressure request is added in, the comparison of the optimal STL curves, with and without $\Delta p$ constraint, is performed and plotted in Figs. 20 25. As indicated in the above Figs. 20 25, it is obvious that to meet the required $\Delta p$ constraint, the acoustical performance (STL) needs to be reduced in order to depress the back pressure in the muffler. As discussed above, the number of chambers in the mufflers will result in a higher STL and a higher back-pressure in the muffler system. A compromise between acoustical performance and back-pressure is required. As defined in Eqs. (7), (17), and (29), the porosity of the open area in the perforated tubes is mostly concerned with the back-pressure value. Any changes of the design parameters such as $d_{1}$ (diameter of duct), $L_{\mathrm{C}}$ (length of perforated duct), $\eta$ (perforated ratio), or $d h$ (diameter of perforated hole) will influence the acoustical performance (STL) and affect the $\Delta p$ directly. 


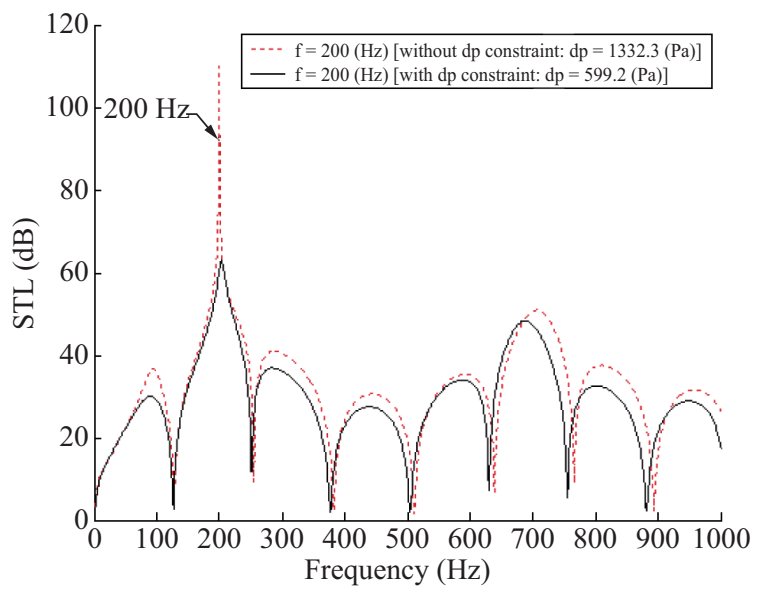

Fig. 20. Comparison of STL curves with and without back-pressure constraint in a one-chamber perforated muffler [targeted frequency $=$ $200(\mathrm{~Hz})]$.

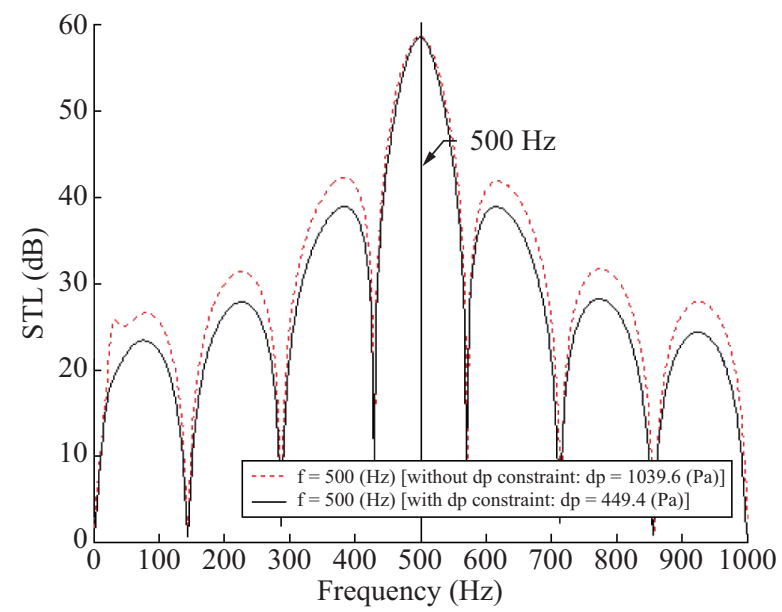

Fig. 21. Comparison of STL curves with and without back-pressure constraint in a one-chamber perforated muffler [targeted frequency $=$ $500(\mathrm{~Hz})]$.

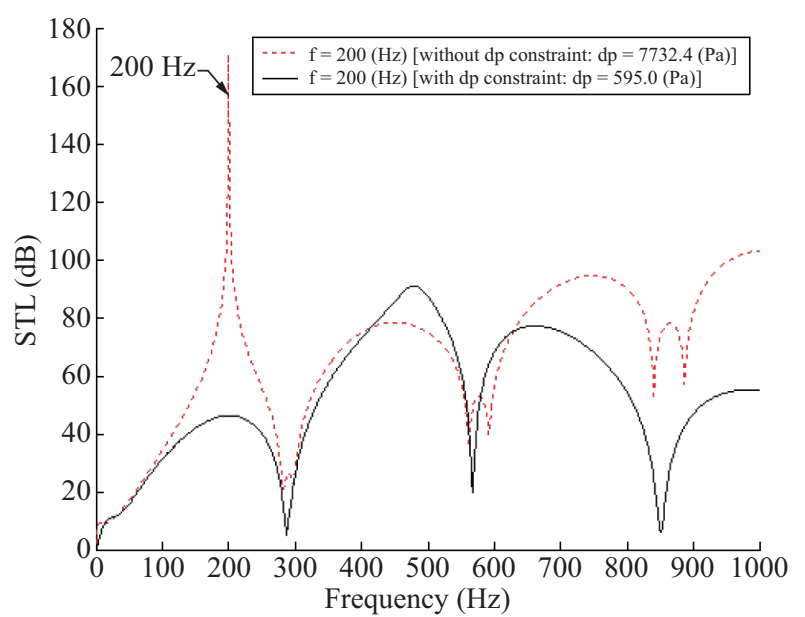

Fig. 22. Comparison of STL curves with and without back-pressure constraint in a two-chamber perforated muffler [targeted frequency $=$ $200(\mathrm{~Hz})]$.

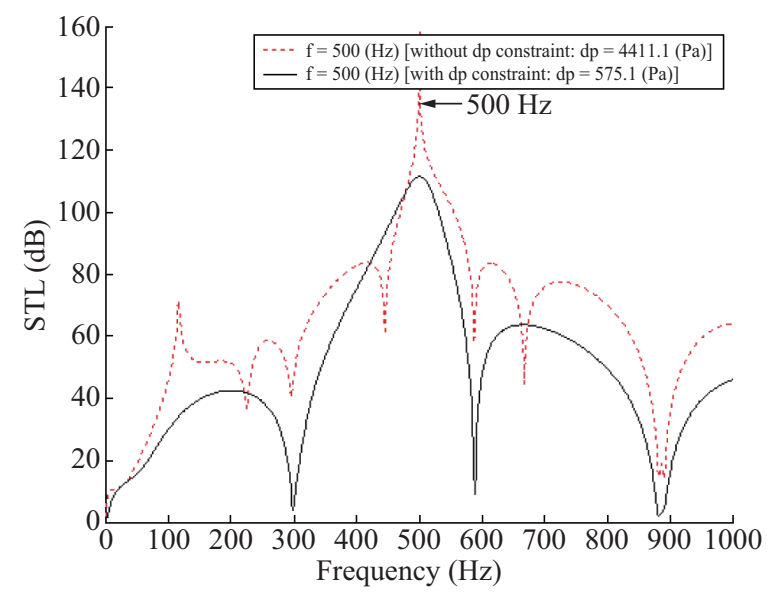

Fig. 23. Comparison of STL curves with and without back-pressure constraint in a two-chamber perforated muffler [targeted frequency $=$ $500(\mathrm{~Hz})]$.

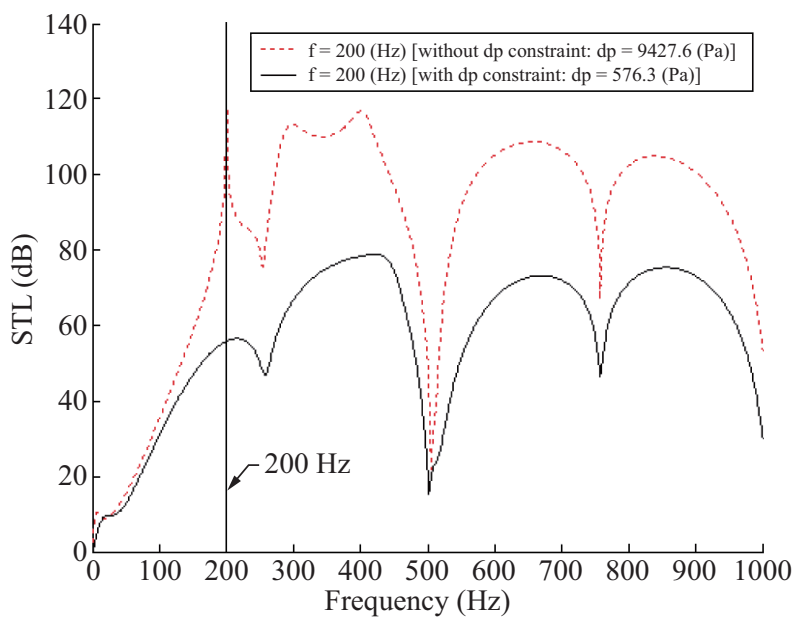

Fig. 24. Comparison of STL curves with and without back-pressure constraint in a three-chamber perforated muffler [targeted frequency $=200(\mathrm{~Hz})]$.

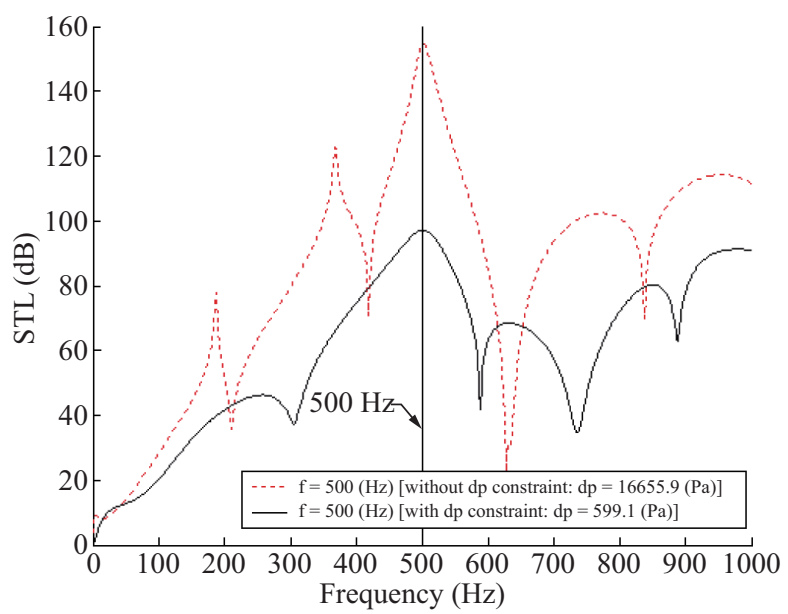

Fig. 25. Comparison of STL curves with and without back-pressure constraint in a three-chamber perforated muffler [targeted frequency $=\mathbf{5 0 0}(\mathrm{Hz})]$. 


\section{CONCLUSION}

It has been shown that multi-chamber mufflers in conjunction with a GA optimizer can be easily and efficiently optimized under space and $\Delta p$ limits by using a generalized decoupling technique, plane wave theory, and a four-pole transfer matrix. Five kinds of GA parameters - pop, iter $_{\max }$, bit, $p c, p m t$ - play essential roles in the solution's accuracy during GA optimization. As indicated in Figs. 13, 14, and 15, the tuning ability established by adjusting the design parameters of the three kinds of mufflers is reliable. To appreciate the relationships between $\mathrm{STL}, \Delta p$, and the design parameters, three kinds of mufflers, with and without $\Delta p$ constraint, are investigated. It was found that the number of chambers in the mufflers is in conflict with the STL and $\Delta p$. Here, the increment of chambers of the mufflers will increase the STL and $\Delta p$. Therefore, the compromise of STL and $\Delta p$ during numerical optimization is necessary. Consequently, the approach used for the optimal design of the STL under $\Delta p$ constraint is indeed quite effective.

\section{NOMENCLATURE}

This paper is constructed on the basis of the following notations:

\begin{tabular}{|c|c|}
\hline bit & bit length \\
\hline$C_{o}$ & sound speed $\left(\mathrm{m} \mathrm{s}^{-1}\right)$ \\
\hline$d h_{i}$ & $\begin{array}{l}\text { the diameter of perforated hole on inner tube at } \\
i \text {-th chamber }(\mathrm{m})\end{array}$ \\
\hline$d_{1}$ & diameter of the inner perforated tube (m) \\
\hline$D_{\mathrm{o}}$ & diameter of the resonator chamber $(\mathrm{m})$ \\
\hline$f$ & frequency $(\mathrm{Hz})$ \\
\hline$f_{c}$ & cutoff frequency $(\mathrm{Hz})$ \\
\hline $\mathrm{H}$ & dynamic head $(\mathrm{Pa})$ \\
\hline iter $_{\max }$ & maximum iteration \\
\hline$j$ & imaginary unit \\
\hline$k$ & wave number $\left(=\frac{\omega}{c_{o}}\right)$ \\
\hline$k_{1}, k_{2}, k_{3}, k_{4}$ & coefficients in function $\Gamma_{i}=f_{i} e^{\gamma_{i} x}$ \\
\hline$L_{1}, L_{2}$ & lengths of inlet/outlet straight ducts (m) \\
\hline$L_{A i}, L_{B i}$ & $\begin{array}{l}\text { length of the un-perforated segments at } i \text {-th } \\
\text { chamber }(\mathrm{m})\end{array}$ \\
\hline$L_{C i}$ & $\begin{array}{l}\text { length of the perforated segment at } i \text {-th chamber } \\
\text { (m) }\end{array}$ \\
\hline$L_{o}$ & total length of the muffler $(\mathrm{m})$ \\
\hline$L_{Z i}$ & $\begin{array}{l}\text { length of the } i \text {-th resonator chamber }\left(=L_{\mathrm{Ai}}+\right. \\
\left.L_{\mathrm{Ci}}+L_{\mathrm{Bi}}\right)(\mathrm{m})\end{array}$ \\
\hline$M$ & mean flow Mach number in the straight duct \\
\hline$O B J_{i}$ & objective function \\
\hline$p c$ & crossover ratio \\
\hline$p_{i}$ & acoustic pressure at $i$-th node $(\mathrm{Pa})$ \\
\hline$p m$ & mutation ratio \\
\hline рор & no. of population \\
\hline$Q$ & volume flow rate of venting gas $\left(\mathrm{m}^{3} \mathrm{~s}^{-1}\right)$ \\
\hline
\end{tabular}

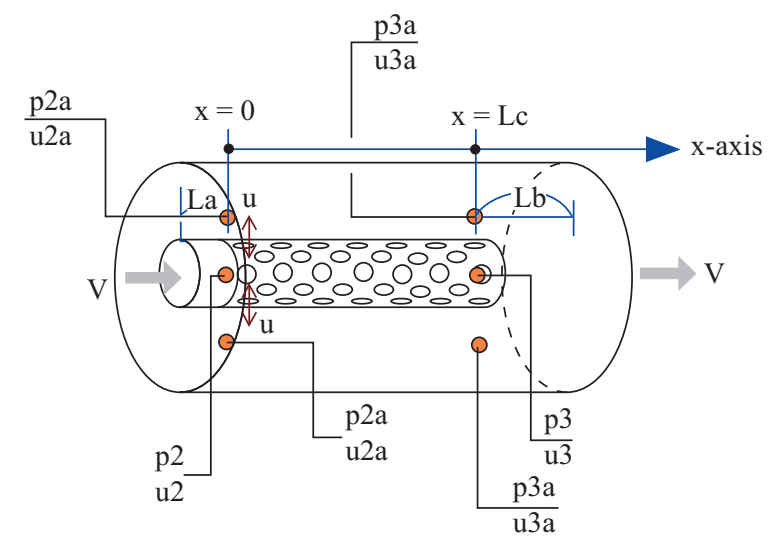

Fig. 26. Acoustical mechanism of a perforated muffler.

\begin{tabular}{|c|c|}
\hline$S_{i}$ & section area at $i$-th element $\left(\mathrm{m}^{2}\right)$ \\
\hline STL & sound transmission loss $(\mathrm{dB})$ \\
\hline$t$ & the thickness of an inner perforated tube (m) \\
\hline $\mathrm{TS} 1_{\mathrm{ij}}, \mathrm{TS} 2_{\mathrm{ij}}$ & $\begin{array}{l}\text { components of four-pole transfer matrices for } \\
\text { straight ducts }\end{array}$ \\
\hline $\mathrm{TP}_{\mathrm{ij}}$ & $\begin{array}{l}\text { components of a four-pole transfer matrix for a } \\
\text { perforated duct }\end{array}$ \\
\hline $\mathrm{T}_{\mathrm{ij}}$ & $\begin{array}{l}\text { components of a four-pole transfer system ma- } \\
\text { trix }\end{array}$ \\
\hline$u$ & acoustical particle velocity in a perforated hole \\
\hline$u_{i}$ & acoustic particle velocity at $i$-th node $\left(\mathrm{m} \mathrm{s}^{-1}\right)$ \\
\hline$V_{i}$ & mean flow velocity at $i$-th node $\left(\mathrm{m} \mathrm{s}^{-1}\right)$ \\
\hline$v_{i}$ & acoustic mass velocity at $i$-th node $\left(\mathrm{kg} \mathrm{s}^{-1}\right)$ \\
\hline xi & open area ratio of inner tube at $i$-th chamber \\
\hline$\rho_{o}$ & air density $\left(\mathrm{kg} \mathrm{m}^{-3}\right)$ \\
\hline$\rho_{2}$ & acoustical density in an inner tube \\
\hline$\rho_{2 a}$ & acoustical density in an outer tube \\
\hline$\varsigma$ & $\begin{array}{l}\text { specific acoustical impedance of a perforated } \\
\text { tube }\end{array}$ \\
\hline$\eta_{i}$ & $\begin{array}{l}\text { the porosity of the perforated tube at ith cham- } \\
\text { ber. }\end{array}$ \\
\hline & ith eigen value of $[\mathrm{H}]$ \\
\hline$[\Omega]_{4 \times 4}$ & $\begin{array}{l}\text { the model matrix formed by an eigen vector } \\
{[\Omega]_{4 \times 1} \text { of }[\mathrm{H}]_{4 \times 4}}\end{array}$ \\
\hline$\Delta p_{a}$ & $\begin{array}{l}\text { allowable maximal pressure drop specified by a } \\
\text { venting system }(\mathrm{Pa})\end{array}$ \\
\hline$\Delta p_{i}$ & mean pressure drop for i-chamber muffler $(\mathrm{Pa})$ \\
\hline
\end{tabular}

\section{ACKNOWLEDGMENTS}

The authors acknowledge the financial support of the National Science Council (NSC97-2221-E-235-001), ROC.

\section{APPENDIX A - Transfer Matrix of Perforated Duct}

As indicated in Fig. 26, the perforated resonator is composed of an inner perforated tube and an outer resonating chamber. Based on Sullivan and Crocker's derivation [15], the continuity equations and momentum equations with respect to inner and outer tubes in a concentric resonator are shown below. 


\section{Inner tube:}

continuity equation

$$
V \frac{\partial \rho_{2}}{\partial x}+\rho_{o} \frac{\partial u_{2}}{\partial x}+\frac{4 \rho_{o}}{D_{1}} u+\frac{\partial \rho_{2 a}}{\partial t}=0
$$

momentum equation

$$
\rho_{o}\left(\frac{\partial}{\partial t}+V \frac{\partial}{\partial x}\right) u_{2}+\frac{\partial p_{2}}{\partial x}=0
$$

\section{Outer tube:}

continuity equation

$$
\begin{gathered}
\rho_{o} \frac{\partial u_{2 a}}{\partial x}-\frac{4 D_{1} \rho_{o}}{D_{o}^{2}-D_{1}^{2}} u+\frac{\partial \rho_{2 a}}{\partial t}=0 \\
\rho_{o} \frac{\partial u_{2 a}}{\partial t}+\frac{\partial p_{2 a}}{\partial x}=0
\end{gathered}
$$

Assuming that the acoustic wave is a harmonic motion, we have

$$
p(x, t)=P(x) \cdot e^{j \omega t}
$$

Under the isentropic processes in ducts, we have

$$
P(x)=\rho(x) \cdot c_{o}^{2}
$$

Assuming that the perforation along the inner tube is uniform (ie. $d \varsigma / d x=0$ ), the acoustic impedance of the perforation $\left(\rho_{o} c_{o} \varsigma\right)$ is

$$
\rho_{o} c_{o} \varsigma=\frac{p_{2}(x)-p_{2 a}(x)}{u(x)}
$$

where $\varsigma$ is the specific acoustical impedance of the perforated tube. According to the formula $\varsigma$, developed by Sullivan [15] and Rao [13], the empirical formulations for the perforates, with or without mean flow, are adopted in this study.

For perforates with stationary medium:

$$
\varsigma=[0.006+j k(t+0.75 d h)] / \eta
$$

For perforates with grazing flow:

$$
\begin{aligned}
\varsigma= & {\left[7.337 \times 10^{-3}(1+72.23 M)\right.} \\
& \left.+j 2.2245 \times 10^{-5}(1+51 t)(1+204 d h) f\right] / \eta
\end{aligned}
$$

where $d h$ is the diameter of perforated hole on inner tube, $t$ is the thickness of inner perforated tube, and $\eta$ is the porosity of the perforated tube.

By substituting Eqs. (A5) (A7) into Eqs. (A1) (A4), we have

$$
\rho_{o} c_{o} \frac{d u_{2}}{d x}=-\left[j k p_{2}+\frac{V}{c_{o}} \cdot \frac{d p_{2}}{d x}+\frac{4 \cdot\left(p_{2}-p_{2 a}\right)}{D_{1} \varsigma}\right]
$$

$$
\begin{gathered}
\rho_{o} c_{o} \frac{d u_{2 a}}{d x}=-\left[j k p_{2 a}-\frac{4 D_{1} \cdot\left(p_{2}-p_{2 a}\right)}{\left(D_{o}^{2}-D_{1}^{2} \varsigma\right)}\right] \\
\rho_{o} c_{o}\left(j k u_{2}+\frac{V}{c_{o}} \cdot \frac{d u_{2}}{d x}\right)=-\frac{d p_{2}}{d x} \\
j \rho_{o} c_{o} k u_{2 a}=-\frac{d p_{2 a}}{d x}
\end{gathered}
$$

Eliminating $u_{2}$ and $u_{2 a}$ by the differentiation of Eq. (A11) and the substitution of Eq. (A12), we have

$\left[\begin{array}{c}\left(1-M^{2}\right) \frac{d^{2}}{d x^{2}} \\ -2 j M k \frac{d}{d x}+k^{2}\end{array}\right] p_{2}-\frac{4}{D_{1} \varsigma}\left[M \frac{d}{d x}+j k\right]\left(p_{2}-p_{2 a}\right)=0$

where $M=\frac{V}{c_{o}}$

Alternatively, Eqs. (A13) and (A14) can also be expressed as

$$
\left[\begin{array}{cc}
D^{2}+\alpha_{1} D+\alpha_{2} & \alpha_{3} D+\alpha_{4} \\
\alpha_{5} D+\alpha_{6} & D^{2}+\alpha_{7} D+\alpha_{8}
\end{array}\right]\left[\begin{array}{c}
p_{2} \\
p_{2 a}
\end{array}\right]=\left[\begin{array}{l}
0 \\
0
\end{array}\right]
$$

Developing Eq. (A15), we have

$$
\begin{gathered}
p_{2}^{\prime \prime}+\alpha_{1} p_{2}^{\prime}+\alpha_{2} p_{2}+\alpha_{3} p_{2 a}^{\prime}+\alpha_{4} p_{2 a}=0 \\
\alpha_{5} p_{2}^{\prime}+\alpha_{6} p_{2}+p_{2 a}^{\prime \prime}+\alpha_{7} p_{2 a}^{\prime}+\alpha_{8} p_{2 a}=0
\end{gathered}
$$

Let

$$
p_{2}^{\prime}=\frac{d p_{2}}{d x}=y_{1}, p_{2 a}^{\prime}=\frac{d p_{2 a}}{d x}=y_{2}, p_{2}=y_{3}, p_{2 a}=y_{4}
$$

According to Eqs. (A16) and (A17), the new matrix between $\left\{y^{\prime}\right\}$ and $\{y\}$ is 


$$
\left[\begin{array}{l}
y_{1}^{\prime} \\
y_{2}^{\prime} \\
y_{3}^{\prime} \\
y_{4}^{\prime}
\end{array}\right]=\left[\begin{array}{cccc}
-\alpha_{1} & -\alpha_{3} & -\alpha_{2} & -\alpha_{4} \\
-\alpha_{5} & -\alpha_{7} & -\alpha_{6} & -\alpha_{8} \\
1 & 0 & 0 & 0 \\
0 & 1 & 0 & 0
\end{array}\right]\left[\begin{array}{l}
y_{1} \\
y_{2} \\
y_{3} \\
y_{4}
\end{array}\right]
$$

which can be briefly expressed as

$$
\left\{y^{\prime}\right\}=[\mathrm{N}]\{y\}
$$

Let

$$
\{y\}=[\Omega]\{\Gamma\}
$$

which is

$$
\left[\begin{array}{c}
d p_{2} / d x \\
d p_{2 a} / d x \\
p_{2} \\
p_{2 a}
\end{array}\right]=\left[\begin{array}{llll}
\Omega_{1,1} & \Omega_{1,2} & \Omega_{1,3} & \Omega_{1,4} \\
\Omega_{2,1} & \Omega_{2,2} & \Omega_{2,3} & \Omega_{2,4} \\
\Omega_{3,1} & \Omega_{3,2} & \Omega_{3,3} & \Omega_{3,4} \\
\Omega_{4,1} & \Omega_{4,2} & \Omega_{4,3} & \Omega_{4,4}
\end{array}\right]\left[\begin{array}{c}
\Gamma_{1} \\
\Gamma_{2} \\
\Gamma_{3} \\
\Gamma_{4}
\end{array}\right]
$$

$[\Omega]_{4 \times 4}$ is the model matrix formed by four sets of eigen vectors $[\Omega]_{4 \times 1}$ of $[\mathrm{N}]_{4 \times 4}$.

Substituting Eq. (A19) into (A18) and then multiplying $[\Omega]^{-1}$ by both sides, we have

$$
[\Omega]^{-1}[\Omega]\left\{\Gamma^{\prime}\right\}=[\Omega]^{-1}[\mathrm{~N}][\Omega]\{\Gamma\}
$$

Set

$$
[\chi]=[\Omega]^{-1}[\mathrm{~N}][\Omega]=\left[\begin{array}{cccc}
\gamma_{1} & 0 & 0 & 0 \\
0 & \gamma_{2} & 0 & 0 \\
0 & 0 & \gamma_{3} & 0 \\
0 & 0 & 0 & \gamma_{4}
\end{array}\right]
$$

where $\gamma_{i}$ is the eigen value of [N]

Eq. (A19) can be thus rewritten as

$$
\left\{\Gamma^{\prime}\right\}=[\chi]\{\Gamma\}
$$

Obviously, Eq. (A22) is a decoupled equation. The related solution becomes

$$
\Gamma_{i}=k_{i} e^{\gamma_{i} x}
$$

Using Eqs. (A2), (A4), (A19), and (A23), the relationship of acoustic pressure and particle velocity becomes

$$
\left[\begin{array}{c}
p_{2}(x) \\
p_{2 a}(x) \\
\rho_{o} c_{o} u_{2}(x) \\
\rho_{o} c_{o} u_{2 a}(x)
\end{array}\right]=\left[\begin{array}{llll}
\mathrm{H}_{1,1} & \mathrm{H}_{1,2} & \mathrm{H}_{1,3} & \mathrm{H}_{1,4} \\
\mathrm{H}_{2,1} & \mathrm{H}_{2,2} & \mathrm{H}_{2,3} & \mathrm{H}_{2,4} \\
\mathrm{H}_{3,1} & \mathrm{H}_{3,2} & \mathrm{H}_{3,3} & \mathrm{H}_{3,4} \\
\mathrm{H}_{4,1} & \mathrm{H}_{4,2} & \mathrm{H}_{4,3} & \mathrm{H}_{4,4}
\end{array}\right]\left[\begin{array}{c}
k_{1} \\
k_{2} \\
k_{3} \\
k_{4}
\end{array}\right]
$$

Taking two cases of $x=0$ and $x=L c$ into Eq. (A24) and doing arrangement yield

$$
\left[\begin{array}{c}
p_{2}(0) \\
p_{2 a}(0) \\
\rho_{o} c_{o} u_{2}(0) \\
\rho_{o} c_{o} u_{2 a}(0)
\end{array}\right]=[\mathrm{A}]\left[\begin{array}{c}
p_{2}\left(L_{C}\right) \\
p_{2 a}\left(L_{C}\right) \\
\rho_{o} c_{o} u_{2}\left(L_{C}\right) \\
\rho_{o} c_{o} u_{2 a}\left(L_{C}\right)
\end{array}\right]
$$

where

$$
[\mathrm{A}]=[\mathrm{H}(0)]\left[\mathrm{H}\left(L_{C}\right)\right]^{-1}
$$

To obtain the transform matrix between the inlet $(x=0)$ and the outlet $(x=\mathrm{Lc})$ of the inner tubes, the two boundary conditions for the outer tube at $x=0$ and $x=$ Lc are taken into calculation and listed below.

$$
\begin{aligned}
& \frac{p_{2 a}(0)}{-u_{2 a}(0)}=-j \rho_{o} c_{o} \cot \left(k L_{A}\right) \\
& \frac{p_{2 a}\left(L_{C}\right)}{u_{2 a}\left(L_{C}\right)}=-j \rho_{o} c_{o} \cot \left(k L_{B}\right)
\end{aligned}
$$

By substituting Eqs. (A26a, b) into Eq. (A25) and developing them, the transfer matrix becomes

$$
\left[\begin{array}{c}
p_{2}(0) \\
\rho_{o} c_{o} u_{2}(0)
\end{array}\right]=\left[\begin{array}{ll}
T P_{1,1} & T P_{1,2} \\
T P_{2,1} & T P_{2,2}
\end{array}\right]\left[\begin{array}{c}
p_{2}\left(L_{C}\right) \\
\rho_{o} c_{o} u_{2}\left(L_{C}\right)
\end{array}\right]
$$

or in brief form

$$
\left[\begin{array}{c}
p_{2} \\
\rho_{o} c_{o} u_{2}
\end{array}\right]=\left[\begin{array}{cc}
T P_{1,1} & T P_{1,2} \\
T P_{2,1} & T P_{2,2}
\end{array}\right]\left[\begin{array}{c}
p_{3} \\
\rho_{o} c_{o} u_{3}
\end{array}\right]
$$

\section{REFERENCES}

1. Alley, B. C., Dufresne, R. M., Kanji, N., and Reesal, M. R., "Costs of workers' compensation claims for hearing loss," Journal of Occupational Medicine, Vol. 31, pp. 134-138 (1989).

2. Chang, Y. C., Yeh, L. J., and Chiu, M. C., "Numerical studies on constrained venting system with side inlet/outlet mufflers by GA optimization," Acta Acustica, Vol. 90, No. 1-1, pp. 1-11 (2004).

3. Chang, Y. C., Yeh, L. J., and Chiu, M. C., "Shape optimization on doublechamber mufflers using genetic algorithm," Proceedings of IMechE, Part C: Journal of Mechanical Engineering Science, Vol. 10, pp. 31-42 (2005).

4. Holland, J., Adaptation in Natural and Artificial System, University of Michigan Press, Ann Arbor (1975).

5. Jayaraman, K. and Yam, K., "Decoupling approach to modeling perforated tube muffler components," Journal of the Acoustical Society of America, Vol. 69, No. 2, pp. 390-396 (1981).

6. Jong, D., An Analysis of the Behavior of a Class of Genetic Adaptive Systems, Doctoral Thesis, Department of Computer and Communication Sciences, University of Michigan, Ann Arbor (1975). 
7. Kaiser, L. and Bernhardt, H., " Noise control on computer and business equipment using speed control blowers," IEEE, Vol. 2, pp. 114-117 (1989).

8. Magrab, E. B., Environmental Noise Control, John Wiley \& Sons, New York (1975).

9. Munjal, M. L., Acoustics of Ducts and Mufflers with Application to Exhaust and Ventilation System Design, John Wiley \& Sons, New York (1987).

10. Munjal, M. L., Krishnan, K., and Reddy, M. M., "Flow-acoustic perforated element mufflers with application to design," Noise Control Engineering Journal, Vol. 40, No. 1, pp. 159-167 (1993)

11. Munjal, M. L., Rao, K. N., and Sahasrabudhe, A. D., "Aeroacoustic analysis of perforated muffler components," Journal of Sound and Vibration, Vol. 114, No. 2, pp. 173-188 (1987).

12. Peat, K. S., "A numerical decoupling analysis of perforated pipe silencer elements," Journal of Sound and Vibration, Vol. 123, No. 2, pp. 199-212 (1988).
13. Rao, K. N. and Munjal, M. L., "Experimental evaluation of impedance of perforates with grazing flow," Journal of Sound and Vibration, Vol. 123, pp. 283-295 (1986).

14. Sullivan, J. W., "A method of modeling perforated tube muffler components I: theory," Journal of the Acoustical Society of America, Vol. 66, pp. $772-778$ (1979)

15. Sullivan, J. W. and Crocker, M. J., "Analysis of concentric tube resonators having unpartitioned cavities," Journal of the Acoustical Society of America, Vol. 64, pp. 207-215 (1978).

16. Thawani, P. T. and Jayaraman, K., "Modeling and applications of straightthrough resonators," Journal of the Acoustical Society of America, Vol. 73, No. 4, pp. 1387-1389 (1983).

17. Yeh, L. J., Chang, Y. C., and Chiu, M. C., "Numerical studies on constrained venting system with reactive mufflers by GA optimization," International Journal for Numerical Methods in Engineering, Vol. 65, pp. 1165-1185 (2006). 